\title{
Visitor Management in World Heritage Destinations before and after Covid-19, Angkor
}

\author{
Antonio Alvarez-Sousa ${ }^{1}$ (1) and Jose Luis Paniza Prados ${ }^{2, *}$ \\ 1 Department of Sociology and Comunications Sciences, Group of Territorial Studies (GET), Sociology Faculty, \\ University of Coruña, 15071 Coruña, Spain; antonio.alvarez@udc.es \\ 2 Department of Sociology, Faculty of Political Science and Sociology, University of Granada, 18071 Granada, Spain \\ * Correspondence: jpaniza@ugr.es
}

Received: 1 November 2020; Accepted: 24 November 2020; Published: 27 November 2020

check for updates

\begin{abstract}
The purpose of this research was to analyze the visitor-management tactics and strategies in World Heritage destinations. The Temples of Angkor (Cambodia) were selected as case studies. The analysis was carried out in two phases-before and after COVID-19. A qualitative methodology was used. Participant observation was employed for the pre-COVID-19 strategies, and recommendations of scholars and bodies responsible for tourism were the basis for the strategies proposed for the post-COVID-19 scenario. Grounded theory and the Atlas.ti qualitative analysis software were used. The results showed that the public health goal, together with its related strategies and tactics, should be added to the classic sustainability goals and the hard and soft strategies (physical, regulatory, and educational). It was also noted that new actors came into play-those responsible for public health. In conclusion, this new public health goal and its tactics will condition classic factors such as carrying capacity, and can conflict with goals such as the economic and social goals. The sustainability paradigm is maintained, but with the addition of risk society and the public health goal playing a key role.
\end{abstract}

Keywords: visitor management; Angkor; COVID-19; risk society; carrying capacity; social distancing; public health; sustainable development

\section{Introduction: Contextualization and Objectives}

In recent years, the number of tourists visiting World Heritage destinations has increased exponentially, sometimes causing problems for their sustainable development. The solution to those problems has called for the development of visitor-management strategies. The Cambodian region of Angkor is a good example for the analysis of visitor-management strategies. In fact, it has been used by UNESCO (United Nations Educational, Scientific and Cultural Organization) as a model for the planning and management of tourism issues [1], since, in recent years, it has experienced a rapid growth in tourism. While this has been a source of wealth in the short-term, it can cause sustainability problems in the long run.

Specifically, the project for the restoration of the Phnom Bakheng temple by the United States through the World Monuments Fund in cooperation with the Authority for the Protection of the Site and Management of the Region of Angkor (hereafter APSARA), clearly shows in its drafting the importance of "planification, stabilization and long-term conservation, and visitor management". Those institutions responsible for the planning and management of tourism in Angkor detected carrying-capacity issues. This prompted them to establish entry limits to certain monuments, with a maximum number of visitors at the same time and with rules of behavior for the visit. APSARA has created the "Visitor Code of Conduct" for World Heritage Sites in Angkor in cooperation with other organizations. It includes obligatory recommendations for visitors on-site. The transformation of the Temples of Angkor into a major tourist destination globally must be carried out, while preserving the 
values and respecting their cultural significance. "That end is the management of change within a historical place/site in a manner that retains its values and respects its cultural significance" [2]. For this reason, we chose Angkor as the object of study in order to analyze the visitor-management strategies.

The COVID-19 pandemic caused a drastic drop in the number of visitors. The temples were left virtually empty of visitors, and now the time has come to bring them back with confidence-building measures in the destination. Appropriate hygiene and social distancing strategies must be added to the classic visitor-management strategies for sustainable development in order to achieve the goal related to public health and bring tourists back, but avoiding potential infection. The assumption here is that they will not be temporary and short-term strategies, but the heavy impact of COVID-19 on tourism globally will remain in the future, although it will be attenuated by the medical discoveries expected.

All these approaches and this contextualization inevitably raise questions that emerge and that this study intends to answer. Some of these questions are as follows: What visitor-management tactics, strategies, and objectives were in place in overcrowded World Cultural Heritage destinations before COVID-19? Are there alternative proposals for the classic strategies and objectives after COVID-19, or are they complementary proposals? Are organizations in charge of tourism and public health echoing the need for changes in the objectives and strategies? If complementary proposals for the objectives and strategies exist, what is their weight in relation to the classic proposals? Are those objectives and strategies able to modify the existing ones? What players decide about the strategies to be followed, the classic tourist sector players, or the new players in charge of national and international public health? Is it necessary to abandon the paradigm of sustainability used to develop the classic objectives and strategies? Should it be left as it is, as the pandemic issue is temporary? Is it necessary to complement the classic paradigm of sustainability with one including the risk of pandemics in a structural manner?

The questions posed allowed us to outline and organize the objectives of the research. They all refer to Angkor, one of the most important areas of the world as far as cultural heritage is concerned. It can serve as a model for other World Heritage Sites, as recognized by UNESCO (2020) [3]. The overall objective of this study is to identify, analyze and compare the visitor-management objectives, strategies and tactics in place before and after COVID-19. The specific objectives are as follows:

(1) To identify the visitor-management objectives, tactics, and strategies in place before COVID-19.

(2) To identify and compare the weight of the new objectives and strategies (post-COVID-19) in the global tourist system, if they come into conflict with those in place prior to COVID-19.

(3) To develop a proposal for an adaptation in the post-COVID-19 era following the recommendations of the specialized bodies.

(4) To analyze the forms of power on which the different strategies are based.

(5) To identify the players who dominate the tourism scenario, establishing if they are those responsible for the sector, or if new external actors come into play and determine the strategies of the sector.

(6) To analyze if the classic paradigm of sustainability used to establish the strategies is maintained, if it is necessary to make changes without abandoning the paradigm, or if it is necessary to create a brand new paradigm.

In this article, the study of the objectives, strategies and tactics was carried out using a qualitative methodology, in two phases. For the first phase, prior to COVID-19, the data collection was done by using participant observation. We went as visitors in order to analyze what visitors encounter when they visit that destination, and the visitor management which affects their behavior. For the second phase-post-COVID-19-the proposals of international bodies specialized in the subject were analyzed, such as the World Travel Organization (WTO) and World Travel and Tourism Council (WTTC). Moreover, the adjustments to the visitor management best practices for tourist visits certification proposed by the Spanish Tourism Quality Institute (ICTE) were analyzed, since it is a body with substantial international experience in certification and risk management issues. 
In an attempt to make what is happening in Angkor useful for other places, grounded theory was used as a data analysis methodology in order to extract general strategies through an inductive process.

\section{The Transformation of the World and Tourism Due to COVID-19 and Its Implications for Visitor Management}

In the aftermath of COVID-19 the world will undergo dramatic change that will affect the globalization process [4] and the structure of society in general. It will also have a dramatic impact on tourism both at the macro level, affecting tourist movements and structures [5] and also regarding specific visitor practices, and therefore visitor management. This will condition the definition of itineraries, the visits to certain places, the ways of looking, touching, feeling and ultimately relating to others. For this reason, we can speak of a pre-COVID-19 era and a post-COVID-19 era in the tourist sector.

\subsection{Paradigms of Visitor Management Pre- and Post-COVID-19}

The paradigm concept enunciated by Kuhn [6] was used with different meanings. Kuhn himself described it in his "Postscript" to "The Structure of Scientific Revolutions". Apparently, the different meanings must include a certain level of agreement between the scientific communities, as well as topics with objectives, assumptions, methodologies and forms of assessment. There is no agreement among different authors in regard to how paradigms appear and persist or are replaced by others. In natural sciences there is a greater tendency to consider that old paradigms are replaced by new ones. A normal science period is followed by an exceptional one until the old paradigm is replaced by a new one that will undergo the same process. In the case of social sciences, many authors consider that different paradigms can be used at the same time.

Before the outbreak of COVID-19, the dominant paradigm in tourism was the paradigm of sustainability. The international organizations which made recommendations about the planning and management of tourism worked under this paradigm. Noteworthy is the special relationship between WTO and UNESCO. Ethical codes for the different actors, recommendations on planning, management, monitoring, development of indicators to measure different sustainability concepts; all this was applied both by those responsible for tourism consultancy and by researchers. Companies, visitors and managers considered the postulates of sustainability in its different fields-social, economic and heritage (cultural and natural). This was also applicable to visitor management. Many different ways to manage visits and visitor flows were developed in order to prevent negative effects on the economy, the quality of life of the residents, the infrastructures, the natural or cultural tourism resources, and tourist satisfaction.

With the outbreak of COVID-19, there was a collapse in tourism globally, even in those areas with management issues due to an excess of visitors—overtourism — that had been echoed by the different organizations (WTO and WTTC), the media, non-governmental organizations engaged in monitoring sustainability, and even governments and organizations responsible for the management of tourism. The advent of COVID-19 raises a different problem. During the peak of COVID-19 the destinations were left empty of visitors. Traveling was impossible because movements and gatherings of people were considered to cause the spread of the virus.

When tourism recovers with an interest in returning to the new normal of people enjoying their trips and economic regeneration, visitor management will have to include new practices so that visitor behavior and flow organization are prepared to prevent the virus being spread and transmitted. Moreover, it is necessary to build confidence so that destinations can attract visitors. This will only be possible if infrastructures are adapted in order to promote a visitor management that can prevent risk and introduce appropriate visitor behavior. The infrastructures and the behavior can even be subject to protocol and certification in order to eliminate risk — to the extent possible - and promote a positive image of the site, and therefore attract visitors. 
Apparently, this new visitor management with the preparation of infrastructures and the generation of preventive behavior by visitors, as well as an emergency response in the event of problems, has come to stay. Even if COVID-19 vaccines are developed, the infrastructures and behavior established by visitor management will survive into the future, since the impact of the pandemic has been immense and has shown that similar problems can arise at any time.

To the paradigm of sustainability, which will remain in the future, we can now add the paradigm of risk society. Although it has been theoretically strong for years [7], it had not been given the same importance that it is taking on now, mainly in the field of tourism. Issues were resolved from a disaster perspective, as something partial and exceptional, not as something general—it affected everybody-and persisting, as similar situations that science cannot control are likely to occur. Therefore, there is a transition from the management of partial and exceptional disasters to a persistent and global risk society. Furthermore, it is necessary to end the separation of the different sciences, so that all of them are complementary and work together to overcome problems. COVID-19 showed that, in the absence of a possibility to develop medical solutions in the short-term, social measures such as isolation, social distancing, and hygiene practices turned out to be the valid solutions.

\subsection{The Paradigm of Sustainability and Flow Management in Overcrowded Destinations with Overtourism Problems}

In the 21st century tourism went from an economic positivism paradigm-all that mattered was the number of visitors and the large figures in the movement of capital, without concern for the implications for visitors, local communities, resources and infrastructures-to a paradigm of sustainability-economically efficient, socially redistributive, genuine and friendly regarding the natural and cultural environment, and politically in line with the principles of governance. While this paradigm shift can be observed in the scientific community [8-10], its internalization by a large number of public and private tourism managers will take some time. However, numerous success stories can be found in different countries [11,12]. Some of them choose approaches such as adaptive co-management. The results of the "Atlas World Heritage" project [13] are of particular interest to the research concerning the practices for the management of destinations with overtourism problems. After an analysis of the situation in five European cities, different strategies were suggested for the management of overtourism in art cities. Such strategies were divided into three sections: accommodation policies, monitoring tactics and promotional offerings.

When tourist destinations are overcrowded, problems regarding carrying capacity and overtourism occur, making it necessary to address them with strategies limiting the number of visitors, as well as managing visitor behavior during the tour-visitor management.

UNESCO proposed a guide for sustainable tourism in World Heritage Sites. This guide comprises ten sections. The most interesting ones for this research refer to developing effective governance (Section 3) and mainly the section on managing visitor behavior (Section 8). Point 5 in Section 8 is of particular interest-methods to consider using for managing visitors. It refers to the following aspects: (a) limit visitor access; (b) spread visitors spatially and across time, to minimize the intensity of negative impacts; (c) advance ticketing systems; (d) congestion-related pricing systems; (e) spreading visitors across the destination; and (f) offer visitors other experiences, products, and services, to lessen the urgency and focus on a small number of "must see" elements.

Different authors analyzed visitor management. There are differences among them according to the strategies proposed. However, although a lot of the literature is being produced at the working level, with concrete tactics in order to manage visitor movements and behavior, there is no meaningful development theoretically. At the applied level, there are also important studies both on natural heritage and cultural heritage sites, and specifically archeological sites [14].

In visitor management, both movement regulation (flow management) and conduct (behavior management) must be analyzed [15]. "Visitor management includes the development and implementation of rules and regulations with respect to visitor activity, which in turn provides 
the guidelines for visitors. On the other hand, it also aims to create enjoyable visitor experiences in the hope that visitors will appreciate the value of the site" [16]. Specifically, "visitor management encompasses all the strategies used to disperse or concentrate visitor flow, modify their behavior or provide them with information on the characteristics of the site" [14].

Among the authors who wrote about visitor-management strategies, special mention should be made of Orams [17], Eagles, McCool, and Haynes [18], Mason [19], Manning and Anderson [20], and the UNESCO guide mentioned earlier. Now, let us present their theories. They will help us be aware of different aspects that we can focus on during our participant observation, although we adopt an open attitude towards everything that shows up on-site.

Orams [17] divided tourist-management strategies into four main categories which must be regulated: physical, regulatory, economic, and educational. According to him, although the physical and regulatory strategies are primarily used, considerable potential exists to use the education-based strategy. Physical management strategies are used to control the interaction between visitors and monument structures. There are sites that are sensitive to the presence of visitors, to the possible effects of people who tread, touch, perspire, and weight, so it is necessary to build barriers in order to control access or even proximity. Regulatory management strategies are used to implement rules ranging from warnings to penalizing certain behaviors that can be harmful to monuments. Some examples are as follows: "visitor number restrictions; limits on times and locations; types of visitor activities permitted; land-use zoning; restrictions on the type of equipment permitted; noise levels; speed limits; permits, lease and license requirements; and codes of practice" [17], p. 43. Economic management strategies are applied to use prices as "incentives or disincentives to modify people's behavior" [17], p. 43. The author described the following tactics as examples: "discounts on admission prices could be used if groups undertake a clean-up project, or assist with research, during their visit, while entry fees could be more expensive during times when wildlife are more sensitive to disturbance. Given the increasing financial pressure under which many public management agencies find themselves, the opportunity to utilise economic techniques to generate additional funds and accomplish management objectives at the same time may become more attractive" [17], p. 44. Educational management strategies are used to reduce inappropriate behavior of visitors "by encouraging a voluntary behaviour change and to increase visitor enjoyment and understanding" [17], p. 44). He mentioned the following tactics as examples: "firstly, control visitor interaction with wildlife; secondly, increase tourist enjoyment and understanding of the experience; and, thirdly, foster a change in tourists' attitudes and behavior" [17], p. 44.

Eagles, McCool, and Haynes [18] proposed a wide variety of strategies (eight in total) and tactics-techniques (37). The strategies are "reduce use of the entire protected area; reduce use of problem areas; modify the location of use within problem areas; modify the timing of use; modify type of use and visitor behavior; modify visitor expectations; increase the resistance of the resource; maintain/rehabilitate the resource." In general, they focus on protected wilderness areas, but most of them apply also to cultural heritage sites. For example, regarding the tactic "require certain skills and/or equipment", we consider that visiting certain cultural sites can also require some form of previous training so that the visit is made responsibly. This is the case for the pilgrim route to Santiago de Compostela, which requires physical and spiritual preparation, as well as equipment.

Mason [19], "focusing specifically on interpretation and codes of conduct in protected natural areas in New Zealand, Australia and Antarctica, argued that the traditional approach of managing visitor impacts should be supported by a far greater emphasis on managing visitor experience". He proposed "placing emphasis on managing visitor experience should allow a more holistic perspective to be employed, in which the visitor can be put within a context that includes both the destination community and the environment visited". Such an approach "should not only lead to better informed and behaved visitors, but a reduction in negative visitor impacts" ([19], p. 181).

Manning and Anderson [20] proposed four strategies. First, increase the supply of recreation areas, for example, providing more trails or expanding the area available for visits. This would help redistribute the impact on the space. Second, reduce demand or permission to be given access 
to certain areas. In this second case, those areas with the most negative impact should be studied. Third, redistribute use patterns, dispersing visitors or concentrating them in specific areas as necessary. Fourth, enhance the resistance of the most frequented areas.

We do not wish to end without alluding to replica models, used as a solution in visitor management in very extreme cases, where the tourist resource is very sensitive or has reached such a high degree of visits that its continuity is in danger [21]. One of the most emblematic cases of replica models are the rock paintings of the Altamira caves in Spain.

The ability of the organizations to exercise the power to implement strategic visitor-management actions must be backed up by some sort of legitimacy. The typology we consider most appropriate is that of Suchman [22]. It identifies three primary types of legitimacy: pragmatic, moral (broken down into four subsections: consequential, procedural, structural, and personal), and cognitive. Sometimes, ensuring the sustainability of a certain place involves making decisions that are not accepted by all the actors concerned. However, it has to be done, and that can be achieved if the decision-making institution is based on a clear legitimacy. In the case of World Heritage destinations, "The authority and capacity to control or prevent Outstanding Universal Value (OUV) damaging activities-which often includes making tough, perhaps even counterintuitive, decisions and enforcing them ... when it is necessary" [1].

As a critique of these visitor-management models prior to COVID-19, we must say that they focus primarily on formal strategies, but do not link them to the sustainable tourism model goals in general. Thus, it is necessary to move towards a model which links the strategies to the sustainable development goals.

\subsection{The Paradigm of Risk Society That Will Determine Carrying Capacity and the Planning and Management of Tourism in the Future}

The COVID-19 crisis paralyzed tourism around the world, and also in areas with many visitors, such as Angkor. Tourism will recover in the future, and visitors will continue to travel not only to familiar places nearby which they consider to be more controlled, but also to other parts of the world, as long as they perceive that the infrastructures are properly prepared and that there are behavior practices that do not entail risks for themselves, the workers, and the destination community. Certifications will even be extended in order to show that the necessary protocols are established for it.

Many tourist locations were prepared for certain exceptional disasters that had occurred in the past, or for certain crisis, but not for a society at global risk. Various authors [23-25] differentiate between crisis and disaster. A crisis is due to inefficient management by the responsible actors in the area of tourism or other agents who are external to the organization, while a disaster involves the unpredictable and is something external to management efficiency. Disasters can generate crises, mainly if there is no prior planning.

A crisis can be solved with the introduction of efficient management, internal or external to the specific tourist organization in crisis, restoring the confidence of the different actors. A crisis can be prevented from happening; in most cases-from a fatalistic perspective-a disaster is unpredictable and difficult to deal with before it happens. However, it is possible to have plans so as to be prepared and take action in case it happens. In other words, a disaster cannot be prevented, but its impact can be limited if a planning exists in order to respond should it occur.

Disasters can happen due to different factors such as tsunamis (as was the case in Southeast Asia in 2004), volcanos (like the one that affected Japan and Hawaii in 2018), floods, and epidemics (like SARS). However, it had always been something localized and limited in time. Maybe SARS was the most widespread, but even in that case it was analyzed by mainly using catastrophe theory [26]. Even in those cases where the fact was called using the concept of risk [27], the risk was not assessed using the concept of global risk society, but as a specific, limited, restricted, manageable risk. Those previous studies about crisis, disasters and risks are well developed, but they focused on a pre-COVID-19 society. Now they must be revisited so that they focus on the different feelings and behaviors of 
people faced with an unusual phenomenon that paralyzed the world. This entails the adaptation of infrastructures and the management of the behavior of visitors and the community that is in contact with them. That can only be understood from the risk society perspective, where consideration should be given not only to the risk that has already occurred (COVID-19), but also to the image that remains and to the potential risks that people think may occur [7].

Risks are global, but their impact and their management must also be observed and implemented locally [28]. The origin of the pandemic was local. It soon spread around the world, with travel and products in a globalized society, but the response to the pandemic is local. Tactics must be introduced at every specific location, at each tourist site that is visited, at Angkor in this case.

With the return to the new normal, the strategies that must be implemented will lead to far-reaching changes, mainly regarding carrying capacity. Tourism carrying capacity is a classic topic in scientific literature on tourism, with important studies both theoretical and applied. Taking Scopus data as the basis, we can see that articles of both types are among the most cited [29-36]. In those articles, there is also an example of the relationship between carrying capacity and overtourism [36].

Coccossis is the author who brings together the largest combination of theoretical and methodological production and practical analysis on the issue. Instead of drawing up an exhaustive list of his works, we can cite as an example of his theoretical and methodological production several chapters included in the book that he coordinated with Mexa [37]. At the applied level, his study on carrying capacity in European tourist destinations is of utmost interest [38].

The sustainable development of tourist destinations, notably in World Heritage Sites, and particularly when they are linked to archeology, sometimes causes the different actors related to the management of the destination to confront one another. The conservators of monuments consider that a massive turnout can be harmful to the resources. In contrast, what politicians, business owners and sometimes local communities want is a large number of visitors who can bring more economic capital to their town [39]. The excess of tourism concentrated in one resource or destination which is not prepared for it causes carrying capacity problems. This concept has been discussed in the literature. Although there are critical views with different alternatives in order to designate various proposals (LAC, Limits of Acceptable Change; and VIM, Visitor Impact Management; VERP, Visitor Experience and Resource Protection), they are in fact complementary [37-40]. Maybe carrying capacity seeks a numeric value, while others such as VIM are "a process of adaptation, which describes desirable conditions and evaluates current activity as a basis for setting tourism management objectives", although "they are closely linked to the basic concept of tourism carrying capacity" ([37], p. 45).

In the case of Angkor, when the Tourism Management Plan (APSARA 2012) [1] was developed, the concept of carrying capacity was repeatedly used. It was subsequently applied to two specific areas in order to limit the number of tickets in Angkor Wat-Bakan and Phnom Bakheng. In addition to the limited number of people, the visitor-management tactics used to manage visitor behavior are consistently indicated all along the way. The aim is to find the conditions permitting visitors to visit the temples and enjoy the visit and its significance, but without negative impacts on infrastructures, culture, religion and society. As a starting point for our work, we used the statement published by Angkor's officials within the framework of the International Council on Monuments and Sites (ICOMOS): “The Heritage Management Framework will establish a set of overarching policies that should assist the APSARA National Authority with the conservation and management of Angkor through a process of good decision-making. This in turn will facilitate obtaining assistance and co-operation from other agencies and stakeholders" [41].

They also explain that these policies will address the different aspects of visitor management, taking into account carrying capacity: "policies will be broad-ranging and will cover matters such as conservation principles for natural and cultural heritage, visitor management (through new visitor circuits and improved visitor flow and parking arrangements), commercial activities, the presentation of the site and carrying capacity. Carrying capacity is, of course, a major consideration, as the Angkor World Heritage Site is already challenged by the burgeoning number of tourists; however there are 
opportunities to address tourism impacts by encouraging different tourist behaviour and offering different tourist experiences" [41].

But currently carrying capacity has changed dramatically with the outbreak of the pandemic. In the measurement of carrying capacity, and in the visitor-management strategies, the factor of health-transmission of the virus and social distancing plays a key role in the ranking of factors. Furthermore, there is a conflict in tourist visiting areas between entertainment, catering and accommodation service providers and the authorities responsible for the control of the pandemic.

\section{Methodology}

In Angkor, visitor management was conditioned by the high number of tourists who went there daily to visit the temples. Therefore, before referring to the data collection concerning the form of visitor management, we must mention the overcrowding of the area. Data on two issues were collected: (a) the overtourism context before COVID-19 and the desert-like space after COVID-19, and (b) the visitor-management strategies-the nuclear issue of this article.

For overtourism before COVID-19, we used statistical data on the evolution of ticket sales and the observation during our visit, which are shown in the photos (Figure 1, left side-Before COVID: Overtourism). With the advent of COVID-19 a dramatic change took place, and the temples went from being overcrowded to being deserted. In order to see the state of the temples after COVID-19 we used two types of sources: the photos and the testimony of a group of visitors who were visiting the temples right before the lockdown, as well as the information given by the media in dates after the lockdown (Figure 1, right side-After Covid: Deserted). The information given by the group of visitors was limited to this fact: the photos to see the lack of visitors caused by COVID-19, specifically on 14 March.

As for the visitor-management strategies before COVID-19, we used participant observation of the site by the authors of the article, taking photos of every tactic (see the different figures in Appendix A) and taking notes when necessary. For example, a high number of visitors descending from a temple can be seen in Supplementary (Images B. No. 2:22). We took a note to explain that the mass descent was due to the fact that the keepers asked visitors to descend in order to make room for other visitors.

COVID-19, sanitary measures and social distancing are affecting tourism and visits so strongly that it will necessary to take this fact into account for the management strategies when borders are re-opened and visitors are received again. For this reason, we propose the introduction of new strategies in visitor management, and our proposal is based on the documents drafted by the ICTE. Such body developed 12 guides, of which we used the one related to tourist visits, as we felt that it was the most appropriate, but the tactics proposed are quite similar in all of them.

As for the steps taken by the authors for the data collection, the participant observation technique was used on-site, with a previous field survey phase and a second data-collection phase.

The on-site observation was carried out following all the steps typically taken by visitors, including travel to the site, purchase of the entry ticket, access, parking, and the tour around the temples with the different activities from early morning—usually ticket purchase at 5:00 a.m.—until 7:00 p.m.

The data collection was done in two phases. The first phase was carried out from 7 to 14 November 2017. In this first visit, the aim was to get an overview of the environment in order to become familiar with visitor management and mass tourism in the area. This allowed us to set up a theoretical framework which formed the basis for the subsequent data collection.

The second phase was carried out from 8 to 27 October 2019. In this trip, we focused on covering all the steps taken by a tourist visiting Angkor. Whenever a tactic was identified in the circuit, a photo of it was taken, as well as relevant notes and comments in our field notebook. In some instances, tactics were reproduced in a very similar way in different places. Whenever this occurred, a principle of saturation was applied to avoid repetition.

The data analysis was carried out based on the principles of grounded theory [42,43], trying to extract models which can be applied in similar situations worldwide. The data were introduced in Atlas.ti. Initially, we created citations (photographs for pre-COVID-19 tactics and paragraphs 
with post-COVID-19 proposals). Those citations were associated with codes, and thus the existing visitor-management strategies (pre-COVID-19) or proposals (post-COVID-19) were identified. Such tactics were brought together to form groups, thereby developing the strategies, which correspond to the code groups in Atlas.ti. Those groups were formed based on the objectives pursued and the different ways to realize them with regulatory, physical, or educational strategies. Lastly, we developed an outline with the different objectives, pre- and post-COVID-19, and with the three types of strategies, taking into account the forms of power.

\section{Results and Discussion}

\subsection{The Visit to Angkor-Small Circuit and Grand Circuit}

The visit to Angkor is divided in two circuits-Small Circuit and Grand Circuit (Appendix A Figure A1). It is impossible to cover both of them in one day, visiting the different temples. It is even impossible in two days, as there would only be enough time for a tour using a mechanic means of transport and to visit the entrance of each temple. Moreover, the opening hours are limited, as they essentially coincide with daylight hours. There is another constraint, which is heat exhaustion of visitors, making it very difficult for a person to physically endure from the opening time to the closing time.

It is important to bear in mind that the sale of tickets starts very early in the morning. Before the COVID-19 crisis, it was necessary to get up at 4:00 a.m. and arrive early, in order to be among the first visitors and watch the sunrise. In order to watch the sunset, it was necessary to be back at Siem Reap after 7:00 p.m. Therefore, a visit of at least three days would be necessary to cover the circuit with reasonable enjoyment and attention to detail. In any case, tickets can be purchased for one day, three days, or seven days, not necessarily consecutive, as they may be alternate. Various means of transport can be used to arrive from Siem Reap. There are also different alternatives to make arrangements, such as physical and virtual travel agencies—-there are many in Siem Reap—providing collective means of transport with tourist guides. They can provide individual options too, e.g., a private guide, which is more expensive but can be tailored to your needs. You can also rent a tuk tuk, which gives you the freedom to do it at your own pace.

The circuit is always the same, starting at Angkor Wat and ending at Phnom Bakheng. In all events, it is not a compulsory itinerary, as the visit can be made freely, with the only restrictions being the opening and closing times of the temples, and the limitations to visit the Bakan (maximum 100 people at once; it is advisable not to spend more than $15 \mathrm{~min}$ there) in Angkor Wat and Phnom Bakheng (maximum 300 people at once).

\subsection{Evolution of the Number of Visitors in Angkor}

In Cambodia, the number of international visitors grew so fast that it went from 118,183 to 5,602,157 in 25 years (1993-2017). Taking 1993 as a reference, and comparing it to 2019, we get an increase of $185 \%$ yearly. Taking the data of the 21 st century, starting in 2000 as a reference and comparing it to 2017 , the increase is $61 \%$ yearly. Although it is clear that the increase has been more moderate in recent years, the fact is that the general increase is noteworthy.

As for the distribution of tourism among the different months, it can be seen that tourism is present in Cambodia every month of the year, mainly in November, December, January, February, and March, but particularly in December.

The busiest arrival area is Phnom Penh, the country's capital, where tourists arrive and then go to other destinations. Angkor (Siem Reap) stands out as a specific tourist destination, with more than $38 \%$ of the total number of international tourists visiting Cambodia.

If we analyze ticket sales data in Angkor (Table 1), in six years, the number of tourists visiting Angkor almost doubled overall, as did the ticket sales revenue. In the busiest months-December, January, and February—-the number of visitors who bought a ticket to visit Angkor doubled. 
Table 1. Statistics of international tourists (buying tickets) visit to Angkor and revenue of Angkor ticket sales 2010 and 2016. Source: Authority for the Protection of the Site and Management of the Region of Angkor (APSARA) tourism statistics and prepared by the authors.

\begin{tabular}{ccccccc}
\hline Months & \multicolumn{2}{c}{ Total Number of Tourists (Buying Ticket) } & \multicolumn{3}{c}{ Revenue, USD } \\
\hline - & $\mathbf{2 0 1 0}$ & $\mathbf{2 0 1 6}$ & Change $\mathbf{~ 2 0 1 0 - 2 0 1 6}$ & $\mathbf{2 0 1 0}$ & $\mathbf{2 0 1 6}$ & Change \% 2010-2016 \\
\hline January & 118,929 & 248,035 & 108.6 & $3,531,880$ & $7,151,260$ & 102.5 \\
February & 118,499 & 245,819 & 107.4 & $3,575,940$ & $7,208,140$ & 101.6 \\
March & 107,007 & 207,504 & 93.9 & $3,040,720$ & $5,992,200$ & 97.1 \\
April & 80,068 & 146,196 & 82.6 & $2,207,000$ & $4,148,560$ & 88.0 \\
May & 69,851 & 125,199 & 79.2 & $1,896,680$ & $3,473,720$ & 83.1 \\
June & 64,967 & 119,302 & 83.6 & $1,796,080$ & $3,297,820$ & 83.6 \\
July & 84,565 & 168,215 & 98.9 & $2,300,760$ & $4,605,280$ & 100.2 \\
August & 93,446 & 172,046 & 84.1 & $2,669,700$ & $4,890,700$ & 83.2 \\
September & 66,838 & 130,856 & 95.8 & $1,839,560$ & $3,640,260$ & 97.9 \\
October & 88,940 & 165,548 & 86.1 & $2,510,600$ & $4,684,620$ & 86.6 \\
November & 127,278 & 219,052 & 72.1 & $3,747,580$ & $6,328,340$ & 68.9 \\
December & 103,963 & 249,482 & 140.0 & $3,997,000$ & $7,161,300$ & 79.2 \\
Total & $1,155,055$ & $2,197,254$ & 90.2 & $33,113,500$ & $62,582,200$ & 89.0 \\
\hline
\end{tabular}

Before COVID-19, the first thing we observed when we arrived to Siem Rep, and specifically Angkor, was a high number of visitors. In the early morning, visitors wait in line in the APSARA facilities - even though there are many ticket offices-in order to buy a ticket (it is an individual ticket, each person must buy one, and this includes a photograph taken, on the spot, in front of the ticket office). Afterwards, almost in the dark, in order to avoid light pollution, they run across the bridge over the big lake and enter the walls of Angkor Wat, but without getting inside the temple, trying to be in the front row, facing the small lake where the temple is reflected, and watch the sun rise behind it. Others prefer to position themselves on the stairs and borders of the monument of the library in front of it. After the sunrise comes the visit to Angkor Wat, waiting in line in order to climb to the central part (Bakan). The build-ups of people will recur all along the way in order to visit other temples, but they will not be controlled with a maximum number of visitors until the arrival to Phnom Bakheng, at the end of the day, to watch the sunset. In all events, we observed that the most crowded spots were the sunrise area in Angkor Wat, the ascent to the Bakan-the central part of the temple of Angkor Wat—and the sunset area in Phnom Bakheng. The only one of them with unlimited access is the sunrise area in Angkor Wat, mainly because visitors stand on a dirt floor, but also on the monument of the library, which is not being given, due attention.

With the global situation of COVID-19, and after March 2020, the photographs of the last visitors on the day before the lockdown and the messages sent by the media show a picture of total desolation from mid-March onwards (Figure 1). 


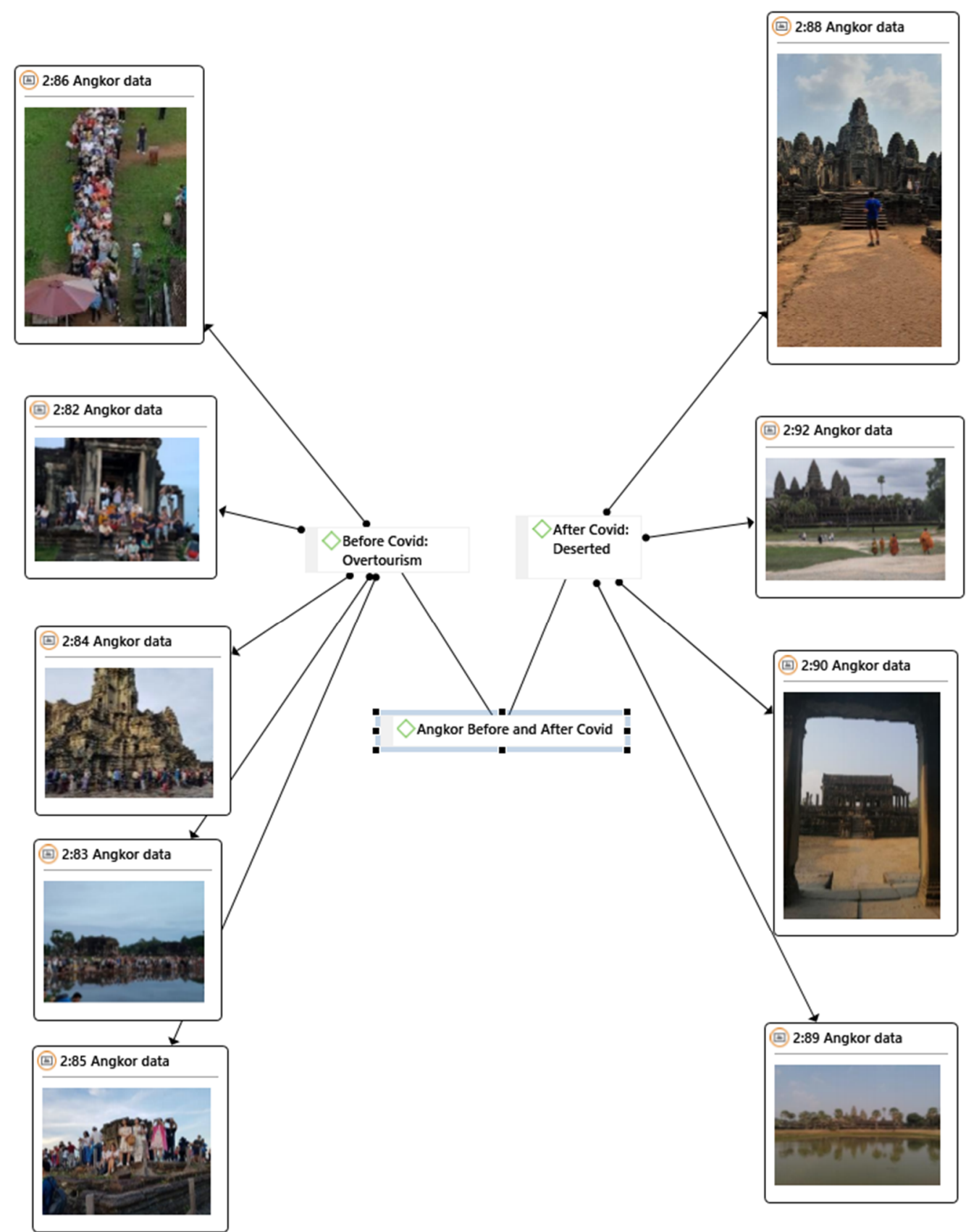

Figure 1. Image of Angkor pre-post Covid-10. Source: prepared by the authors.

\subsection{Visitor-Management Tactics in Angkor Pre- and Post-COVID-19}

In order to compare the situation of visitor management pre-COVID-19 to the one proposed in the post-COVID-19 era, we carried out an analysis of the visitor-management codes which stem from the technical application of participant observation in the pre-COVID-19 era, and the codes resulting from visitor-management recommendations post-COVID-19. As introducing the evidences of the citations would lengthen the article, those evidences are included in the Appendix A with 16 figures which correspond to the networks developed in Atlas.ti.

In the pre-COVID-19 era the codes on which visitor management was based according to our participant observation are shown in Table 2. 
Table 2. Visitor-management tactics pre-COVID-19. Source: prepared by the authors.

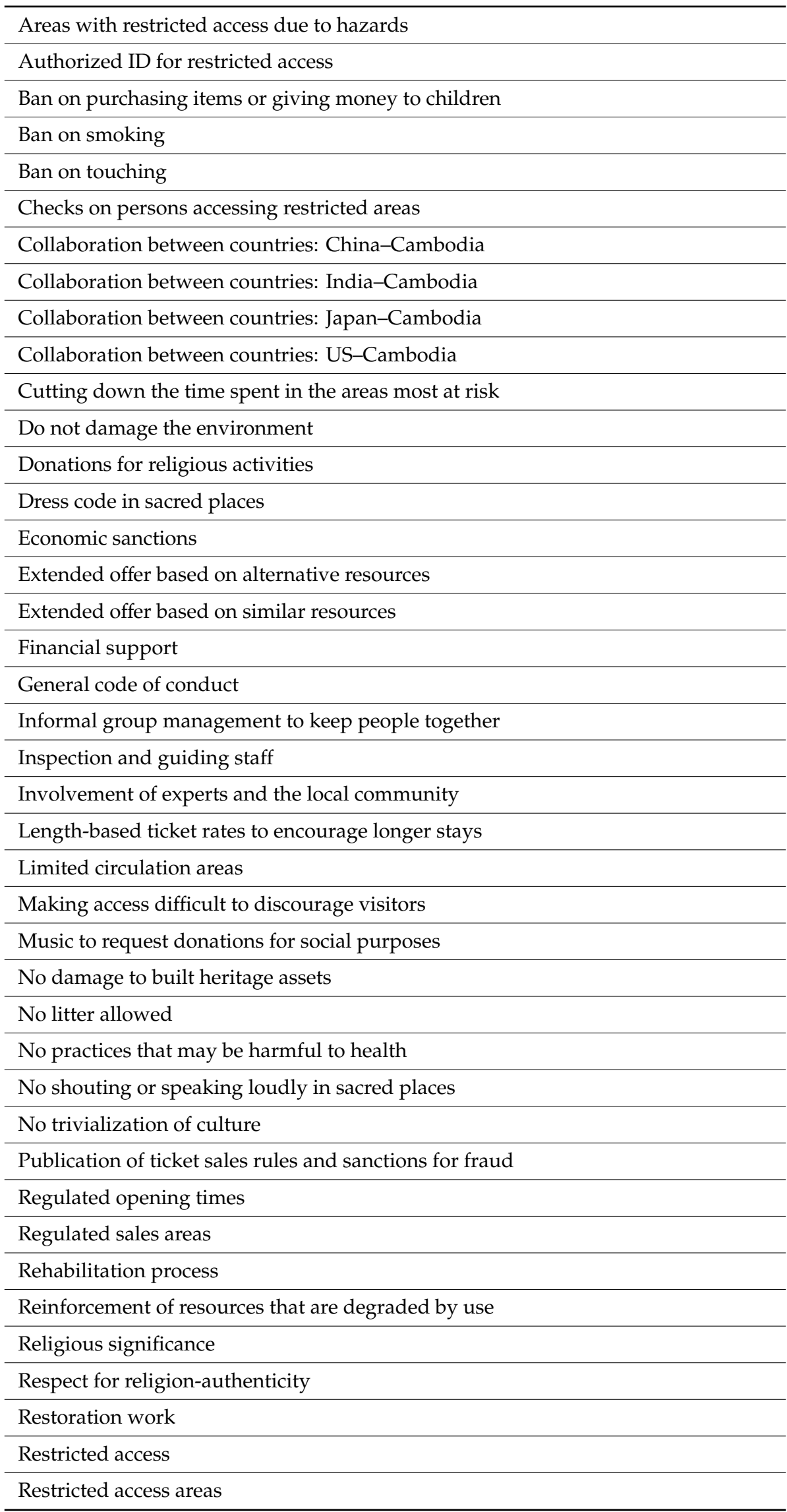


Table 2. Cont.

\begin{tabular}{l}
\hline Restricted area access and waiting times \\
\hline Restricted area access and visiting times \\
\hline Sale of accommodation, food, drink, and leisure in Siem Reap \\
\hline Sale of local produce \\
\hline Sale of services \\
\hline Sale of souvenirs \\
\hline Sense of the universe and everyday life \\
\hline Strengthening of resources against inclement weather and for the safety of tourists \\
\hline Supplementary infrastructures \\
\hline Take care of the natural environment \\
\hline Technical Project \\
\hline Ticket inspections \\
\hline Ticket sales \\
\hline Traffic regulation \\
\hline Transport and guide service sales \\
\hline Visit flow and points of interest \\
\hline
\end{tabular}

In the post-COVID-19 era, the recommended codes for visitor management, in addition to the codes mentioned before, are shown in Table 3.

Table 3. Visitor-management tactics recommended to be added in the post-COVID-19 era. Source: prepared by the authors.

\begin{tabular}{l}
\hline Areas with restricted access due to hazards \\
\hline Avoid physical contact, e.g., shaking hands \\
\hline Brochures and equipment to improve visitor experience, i.e., electronic/disposable \\
\hline Carrying capacity \\
\hline COVID-19 symptoms warning messages \\
\hline Cutting down the time spent in the areas most at risk \\
\hline Sanitizing mats at entrance \\
\hline Disinfectant solution \\
\hline Emergency numbers \\
\hline Emplacement, visit itinerary \\
\hline Extended offer based on similar resources \\
\hline Hygiene waste \\
\hline Information on preventive measures \\
\hline No practices that may be harmful to health \\
\hline Non-contact thermometer \\
\hline Shopping areas controlled and use of protection screens \\
\hline Social distancing \\
\hline Electronic tickets \\
\hline Transport disinfection and social distancing \\
\hline
\end{tabular}


Table 3. Cont.

\begin{tabular}{l}
\hline Use of masks \\
\hline Visitors must sign a declaration of responsibility \\
\hline Visitors need to be informed on arrival of the preventive requirements they should meet \\
\hline Washing hands and disinfectant solution \\
\hline
\end{tabular}

\subsection{Substantive Theory_Visitor-Management Strategies to Organize the Tactics}

Visitor management in a tourist destination needs to be coordinated with the objectives of the plan for that destination. Understanding the visitor-management tactics of a specific destination does not make sense if they are not included as part of the objectives pursued regarding tourism in that destination, which must be included in a plan.

In the case of Angkor, visitor-management tactics are in line with the objectives included in the "Angkor World Heritage Area Tourism Management Plan" (APSARA 2012) [1]. The objectives pursued with that plan are in line with the "Principles for Sustainable Tourism at World Heritage Properties" (APSARA 2012) [1], p. 35.

Based on these objectives, the APSARA established the visitor-management system, carrying out several tactics that were implemented in all the temples, with specific instructions for visitors, "managing visitor activity to ensure the protection and presentation of heritage their values and respect for local communities" (APSARA 2012) [1], p. 35. To this end, it considers that "Firstly, the carrying capacity of the site needs to be regulated. By assessing the carrying capacity of both the World Heritage Park and individual temples or locations, well-informed decisions may be made about access, maximum allowable visitor numbers, visitor flow patterns within the site and temples and limiting factors such as parking and visitor facilities" (APSARA 2012) [1], p. 37. In addition to that, visitors' behavior needs to be regulated so that their conduct contributes to achieving the sustainable development goals through tourism.

In order to give meaning to the broad set of codes laid out-which were established on the basis of evidences-the codes were assigned to categories according to two factors. The first factor refers to the actions which induce visitors, to achieve the classic sustainable development goals. After COVID-19, the goal about contributing to public health by preventing the spread of pandemics was added to them. The second factor refers to the tactics which encourage compliance through physical, regulatory, or educational actions. In some instances, tactics have all three characteristics, as they involve rules for regulation, the availability of physical structures allowing for compliance, and the education of people by promoting the kindness of cooperation. However, in most cases, one tactic prevails.

Table 4 shows the categories that resulted from the mixing of the objectives and the strategies/tactics, which are as follows: economic-physical, economic-regulatory, and economic-educational; social-physical, social-regulatory, and social-educational; cultural heritage-physical, cultural heritage-regulatory, and cultural heritage-educational; natural heritage-physical, natural heritage-regulatory, and natural heritage-educational; public health-physical, public health-regulatory, and public health-educational.

The economic objective (Figure 2) combined with physical tactics (Appendix A Figure A2) can be observed in the different sale points for transport and guide services, in order to get to the temples, in the sale of tickets to enter the temples with a structure offering a lot of ticket offices, in the sale of products inside the temples and around them, both handicrafts and industrial or local products. The economic objective combined with regulatory tactics (Appendix A Figure A3) can be observed in the regulation of the agencies-the official ones offer information but not sales, while the private ones sell transport and guide services, but not tickets, which can only be sold by the official body responsible for the temples-the regulation of ticket prices, the economic sanctions in case of entering without a ticket, and the ban on buying items from children. The economic objective that is conveyed through the educational strategy (Appendix A Figure A4) can be seen in the information received about how the restoration works are financed, the importance of offering economic help to the musicians, and the 
destination of the permitted donations and aids to those responsible for religious practices in places of worship.
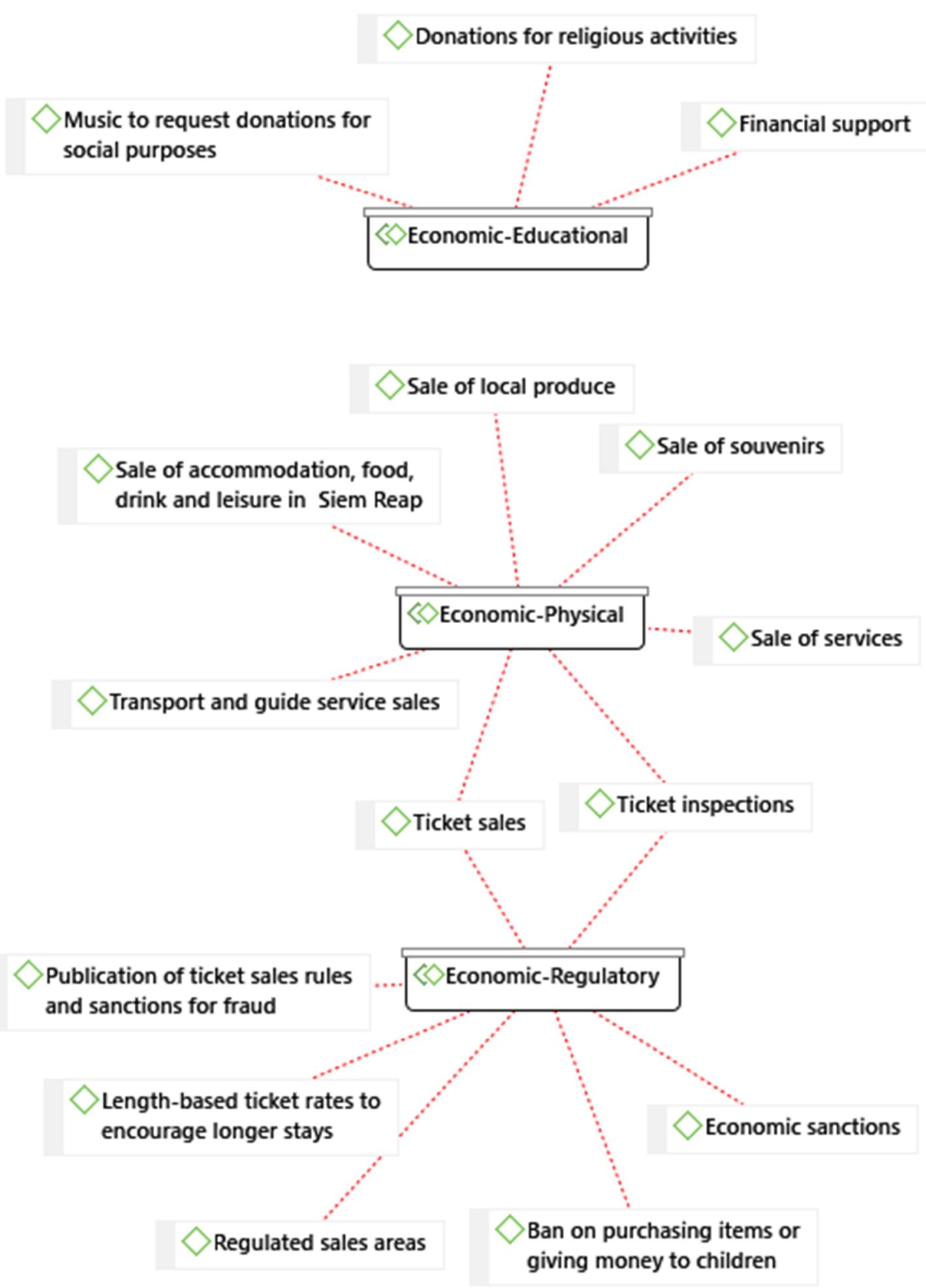

Figure 2. Different visitor-management strategies related to the economic objective. Source: prepared by the authors. 
Table 4. Visitor-management strategies. Source: prepared by the authors.

\begin{tabular}{cccc}
\hline \multirow{2}{*}{ Objectives to Be Achieved } & \multicolumn{3}{c}{ Types of Strategies } \\
\cline { 2 - 4 } & Physical & Regulatory & Educational \\
\hline Economic & Economic-Physical & Economic-Regulatory & Economic-Educational \\
\hline Social & Social-Physical & Social-Regulatory & Social-Educational \\
\hline Cultural Heritage & Cultural Heritage-Physical & $\begin{array}{c}\text { Cultural } \\
\text { Heritage-Regulatory }\end{array}$ & $\begin{array}{c}\text { Cultural } \\
\text { Heritage-Educational }\end{array}$ \\
\hline \multirow{2}{*}{ Natural Heritage } & Natural Heritage-Physical & Heritage-Regulatory & Heritage-Educational \\
\hline Public Health & Public Health-Physical & Public Health-Regulatory & Public Health-Educational \\
\hline
\end{tabular}

The social objective (Figure 3), combined with tactics of the physical strategies (Appendix A Figure A5), can be observed in multiple panels attached to the restoration works. They offer information about the capital stock that was established in order to carry them out, with agreements between countries and organizations. It can also be seen in the management of informal social groups formed mainly in the most crowded places. In the different areas, they are informed of the capacity, the approximate waiting time from their place in the line, and the maximum visiting time they cannot exceed in order to give way to other visitors. The tactics of the regulatory strategy (Appendix A Figure A6), at a social level, can be observed in the code of conduct that is published, drafted under the agreement of the different organizations responsible for the management, particularly regarding aspects such as behavior and dress code: no revealing clothes that are inappropriate for a place of worship, no smoking, no littering. The tactics of the educational strategy (Appendix A Figure A7) are related to visitor awareness about social problems and how they can help: no buying items or giving money to children, so as to encourage them to attend school; no entering restricted areas; no spending a long time in the most crowded places, so that other people can have access to them; collaborate with local services such as musical groups which liven up the atmosphere and can be given donations for social purposes in return; no shouting, but speak in a quiet voice in order not to disturb other visitors or alter the atmosphere of the sacred sites; the communication about the significance of the buildings regarding the sense of the universe and daily life. In other words, the idea is to raise visitor awareness about the relationship with the community and the environment, and also to educate them about the transcendental significance of the place, whose authenticity must be respected.

The objective related to the preservation of cultural heritage (Figure 4) combined with tactics of the physical strategies (Appendix A Figure A8) can be observed in multiple works that are visible all along the way. Some of them are already finished, while others are in progress. There are steps which are heavily worn, but they have been supplemented by wooden steps, so that people do not step on the stone, cornices which have been braced so that they do not collapse, works being carried out by local or foreign workers following a process which is thoroughly detailed in a panel, areas where wear or vandalism caused figures to break which display pertinent instructions to avoid it, and even piles of small stones to make people aware of the fact that they should not touch the stones, even if they are small, as they have their place in the restoration process. The access to places was regulated (Appendix A Figure A9), particularly to the busiest spots, such as the Bakan (maximum of 100 people at once; it is advisable not to spend more than 15 min there) in Angkor Wat and Phnom Bakheng (maximum 300 people at once). People visiting Bakheng must carry their identification badges and give them to a member of the staff when they leave, so that they can be given to another visitor wanting to watch the sunset. There is a prohibition on touching certain carvings and approaching within a certain distance, and opening and closing times are regulated. However, most important is the education of visitors (Appendix A Figure A10), to make them aware of the importance of the temples, of their conservation. To this end, everything is explained on multiple posters, indicating the reasons for the restrictions, the importance of treating the monuments with care so as not to damage them, the areas where transit is permitted of forbidden, the actions taken to attain their current state of conservation, 
and the bodies and even persons involved-the visitor can be one of them. Another important thing is the information encouraging visitors to visit other places similar to Angkor but not as busy, in order to bring life to other areas and avoid the deterioration of Angkor.

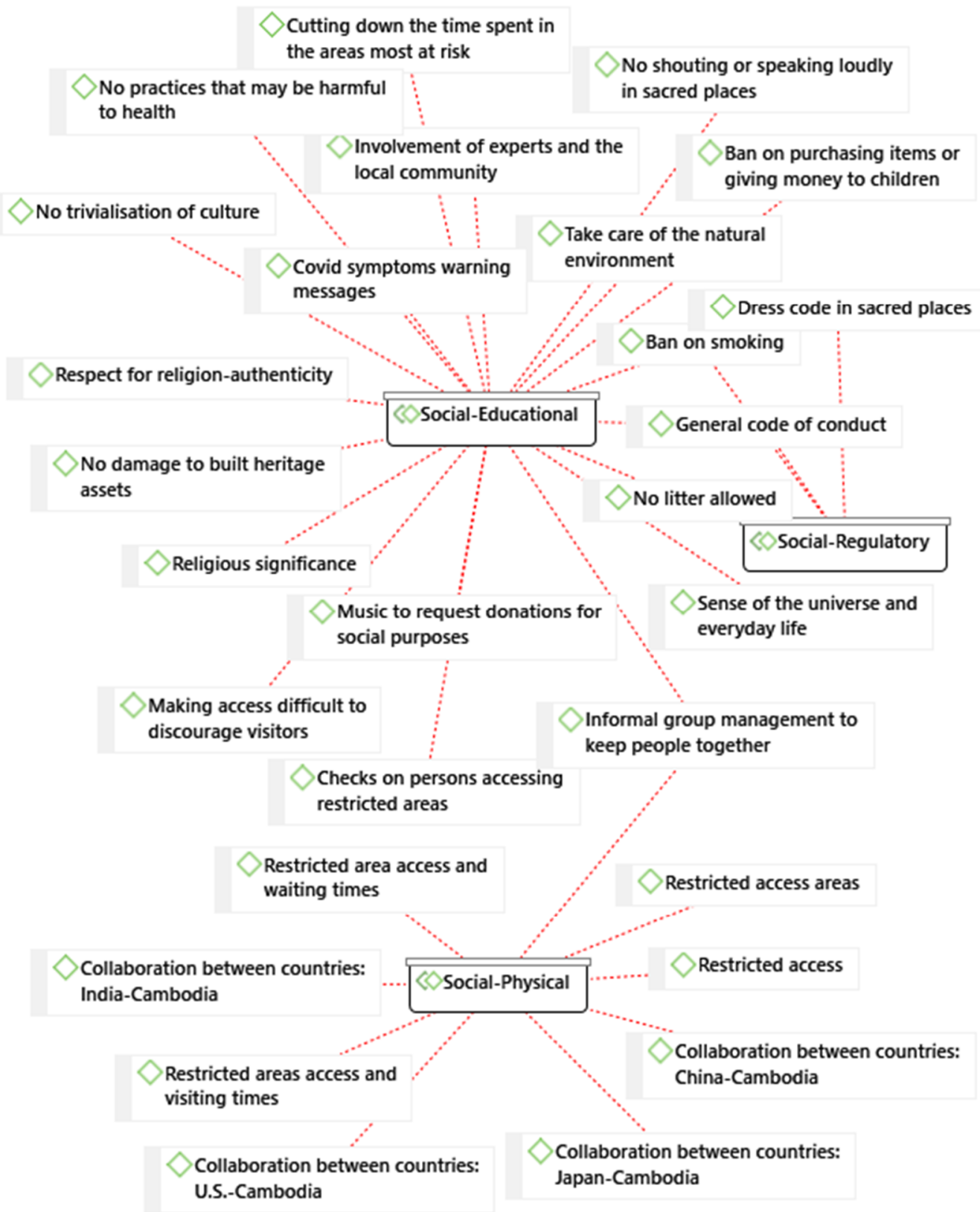

Figure 3. Different visitor-management strategies related to the social objective. Source: prepared by the authors. 


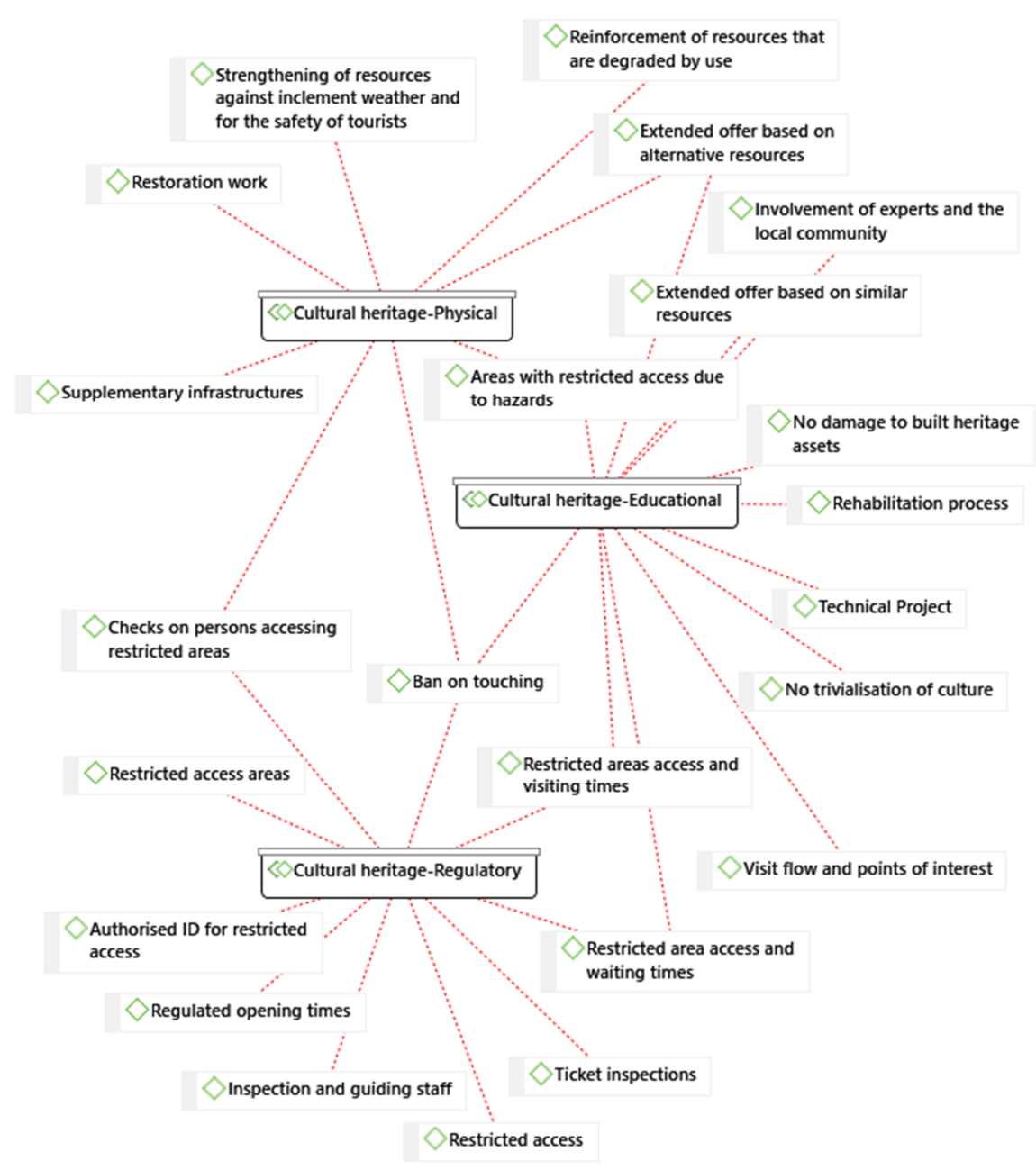

Figure 4. Different visitor-management strategies regarding the objective related to cultural heritage. Source: prepared by the authors.

The objective related to the preservation of natural heritage (Figure 5) combined with tactics of the physical strategies (Appendix A Figure A11) can be observed clearly in Angkor. Although it is a destination associated mainly with cultural heritage, the temples are located in a wide area with important natural heritage, which is being preserved in an increasingly explicit way. Proof of this are the large panels at the entrance of the circuit explaining the interest of nature and the tree species, as well as the institutional actions carried out recently for that with agreements between multiple countries, which even joined a symbolic tree planting. Another important thing is spatial planning for visits and means of transportation in order to avoid damaging the environment. Another major action is the offer to visit natural sites nearby as an alternative or a complement to cultural tourism and a way to solve overcrowding problems in Angkor. This led to traffic regulation strategies (Appendix A Figure A12), as well as the regulation of access to certain temples, which requires walking in the countryside, but on well-established trails with lookouts and instructions to prevent visitors from leaving the circuit. All this has a social an educational effect (Appendix A Figure A13) and raises social awareness, particularly on seeing the trees recently planted by the authorities of the countries that participated in the convention on nature, on seeing the importance of the natural sites on posters encouraging visitors to visit them. We were struck in particular by a group of visitors who were criticizing the attitude of a different group who was having fun with some monkeys. The group of educated visitors was commenting on the need to establish directions to forbid those practices. 


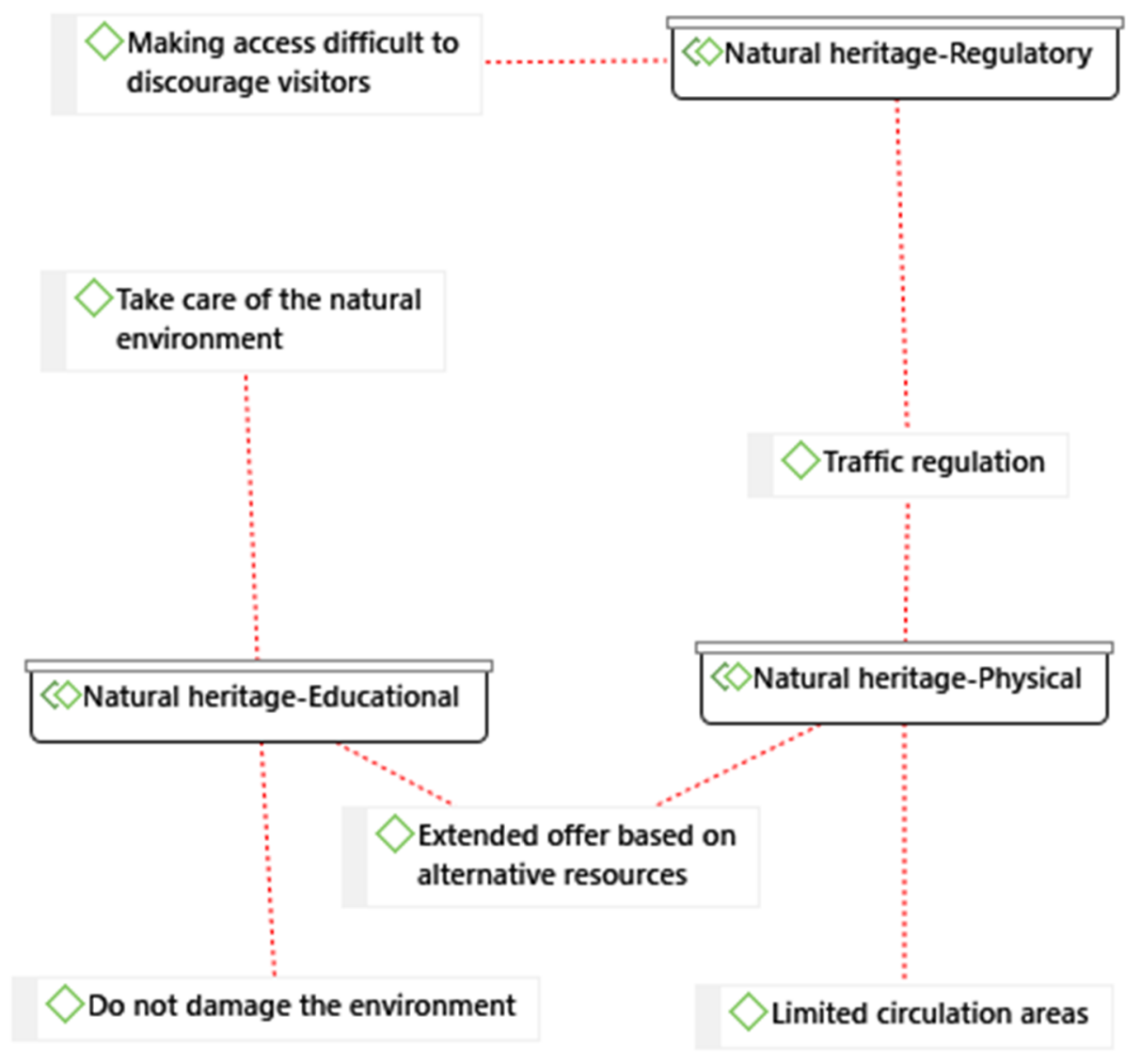

Figure 5. Different visitor-management strategies regarding the objective related to natural heritage. Source: prepared by the authors.

Before COVID-19, the strategies related to health were minimal. They were limited to specific hazard points-electricity and landslides—or health points due to high temperatures or inclement weather for sensitive persons. With the COVID-19 pandemic, it is necessary to establish strategies for the preservation of public health. To this end, after consulting the documents mentioned in the methodology section, different tactics are proposed, which can be included in the regulatory, physical and educational strategies (Figure 6). The regulatory tactics (Appendix A Figure A15) include giving permission to visit the country only to visitors who meet the relevant medical requirements. For the visit to Angkor, on-site ticket sales must be replaced by online sales, and physical tickets must be replaced by electronic tickets. Visitors must sign a declaration of responsibility stating that they meet the hygiene and health requirements. They must have their temperature taken and watch for other symptoms related to the virus. In case of symptoms, they must call the helpline number provided for such purposes and follow the advice given. Furthermore, information must be provided in an electronic form, and to the extent possible visitors must use their own means to view it. In case of using means provided by the organization, they must be disposable. Otherwise, they must be disinfected. Moreover, masks must be worn. All of this must be physically visible (Appendix A Figure A14), with screens in the offices, in case of having to use them, and with the use of masks, mats to disinfect shoes, marked seats in transports, handwashing stations with hand sanitizer, social distancing and avoiding all kind of contact between people or with panels and other types of objects, and particularly with the signs indicating the itinerary so that visitors do not cross paths. The instructions referring to COVID-19 symptoms must also be visible, as well as the non-contact thermometer and, if necessary, the emergency number that must be called in case of symptoms. In addition to establishing public health rules, they must be followed based on awareness (Appendix A Figure A16). To this end, an educational effort is necessary to inform about the preventive measures at the information centers of 
the destination before the visit. Visitors must be informed on arrival—reception of the temples-about the requirements that must be met. Electronic brochures must be provided-a code of conduct similar to the current code, but specific to health. Visitors must be made aware of the importance of social distancing, hand hygiene, waste management, and their relationship with objects.

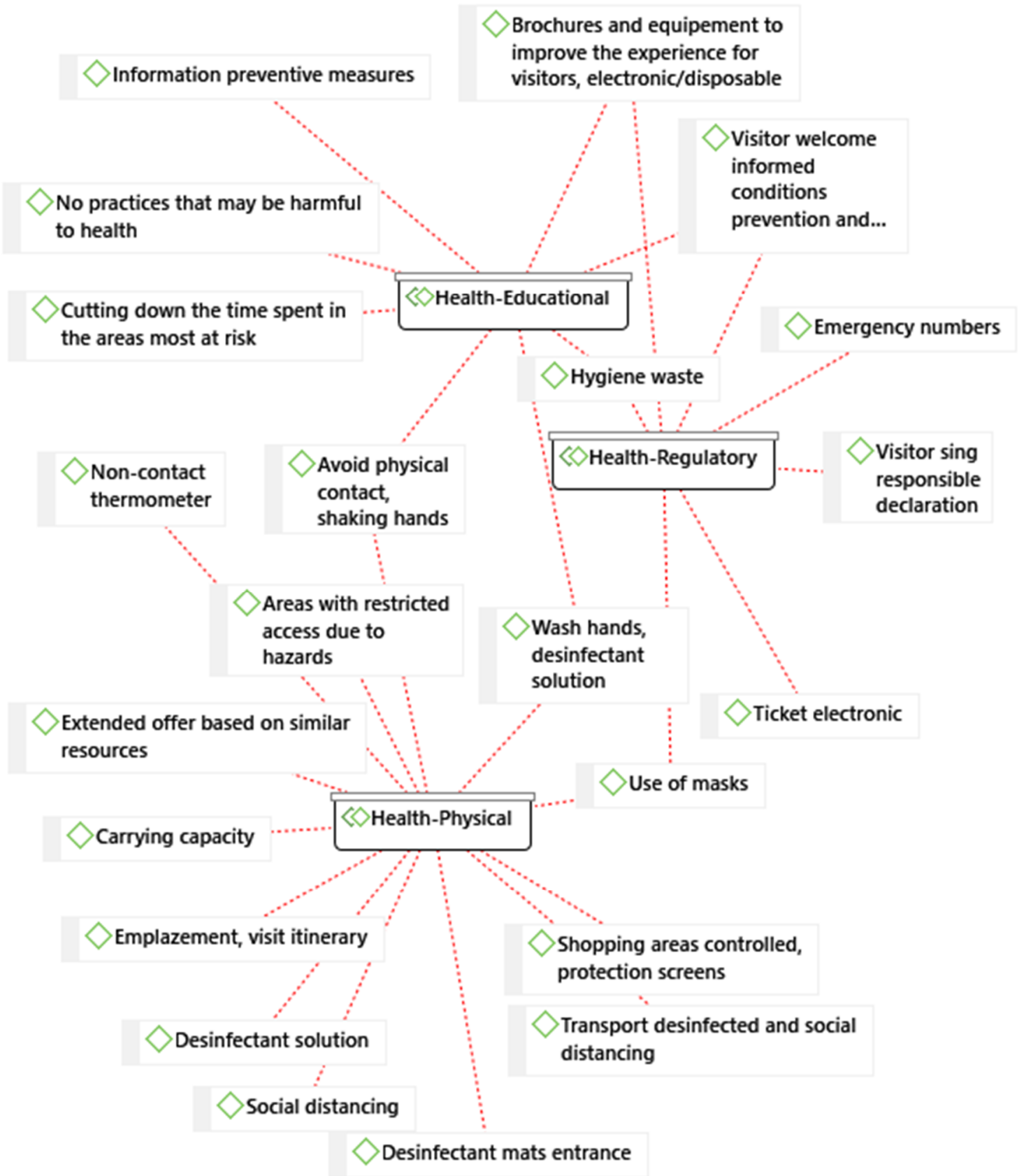

Figure 6. Different visitor-management strategies regarding the objective related to public health. Source: prepared by the authors.

4.5. Formal Theory-Structure of Visitor-Management Strategies Pre-and Post-COVID-19 and Redevelopment of the Paradigm of Sustainability

The principles pursued before the COVID-19 pandemic were related to the community major sustainable development goals to be achieved through tourism-economic (profits), social (equity), natural heritage (sustainability), and cultural heritage (authenticity) (Figure 7). 
Economically, it was intended that tourism would produce financial gains, with different ways of providing services to visitors and ensuring that these profits had a positive impact. There are both large companies-local, regional, national or even international (offering hotels, restaurants, transport, agencies, guides) - and small local companies which make a profit from tourism (tuk tuk, sale of handicrafts, sale of local products of the soil), and even economic benefits for social goods of communities in need, religious groups, etc.

Socially, it was intended that the distribution of profits would ensure that different people could live on the provision of tourist services. Moreover, a large capital stock was developed to strengthen the links inside the community and even between countries-organizations such as APSARA, UNESCO, and delegations of other countries-as well as the relationships between people from the community and people from other parts of the world, and also to foster social mobility of people from deprived backgrounds, allowing them to move out of poverty, etc.

As for heritage, it was intended that tourism would help genuinely retrieve tangible and intangible cultural heritage by adapting it for tourism. However, in the case of Angkor, there is also a great natural heritage. In recent years, efforts are being made to retrieve it through tourism, with sustainability actions for the local flora and fauna.

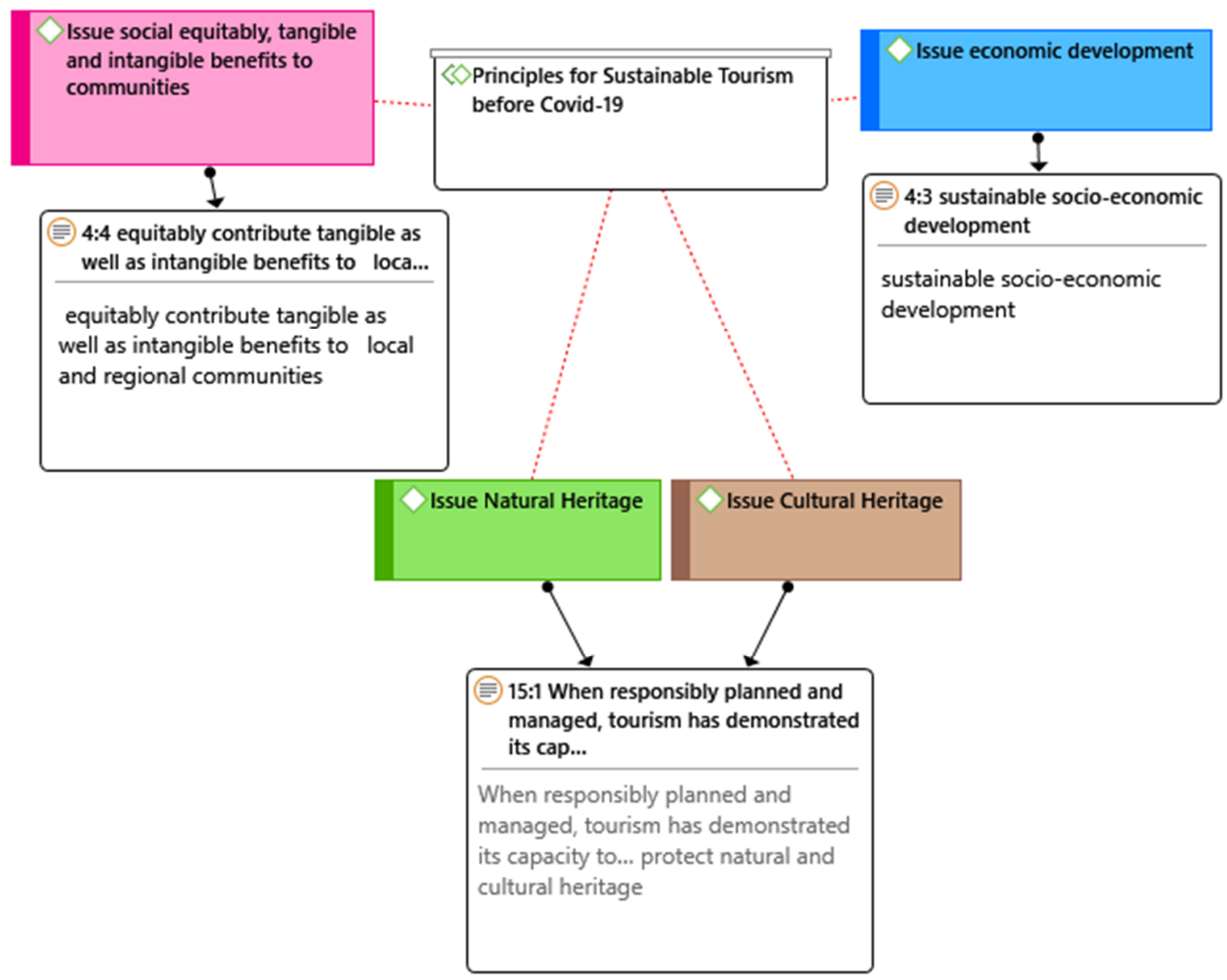

Figure 7. Visitor-management objectives according to the theory of sustainability pre-COVID-19 included in the Angkor Tourism Management Plan. Source: prepared by the authors.

With the outbreak of the COVID-19 pandemic, a new objective is added to all the aforementioned-the objective related to public health (Figure 8). To this end, it is necessary to carry out actions in visitor management, including control at origin. Visas must be granted only to people who meet the appropriate requirements-in the absence of a vaccine, having been subjected with negative results to the tests for the detection of the virus, as well as making a deposit for potential 
situations of contracting the disease; in the presence of a vaccine, providing evidence of vaccination and a copy of the COVID-19 immunization record.

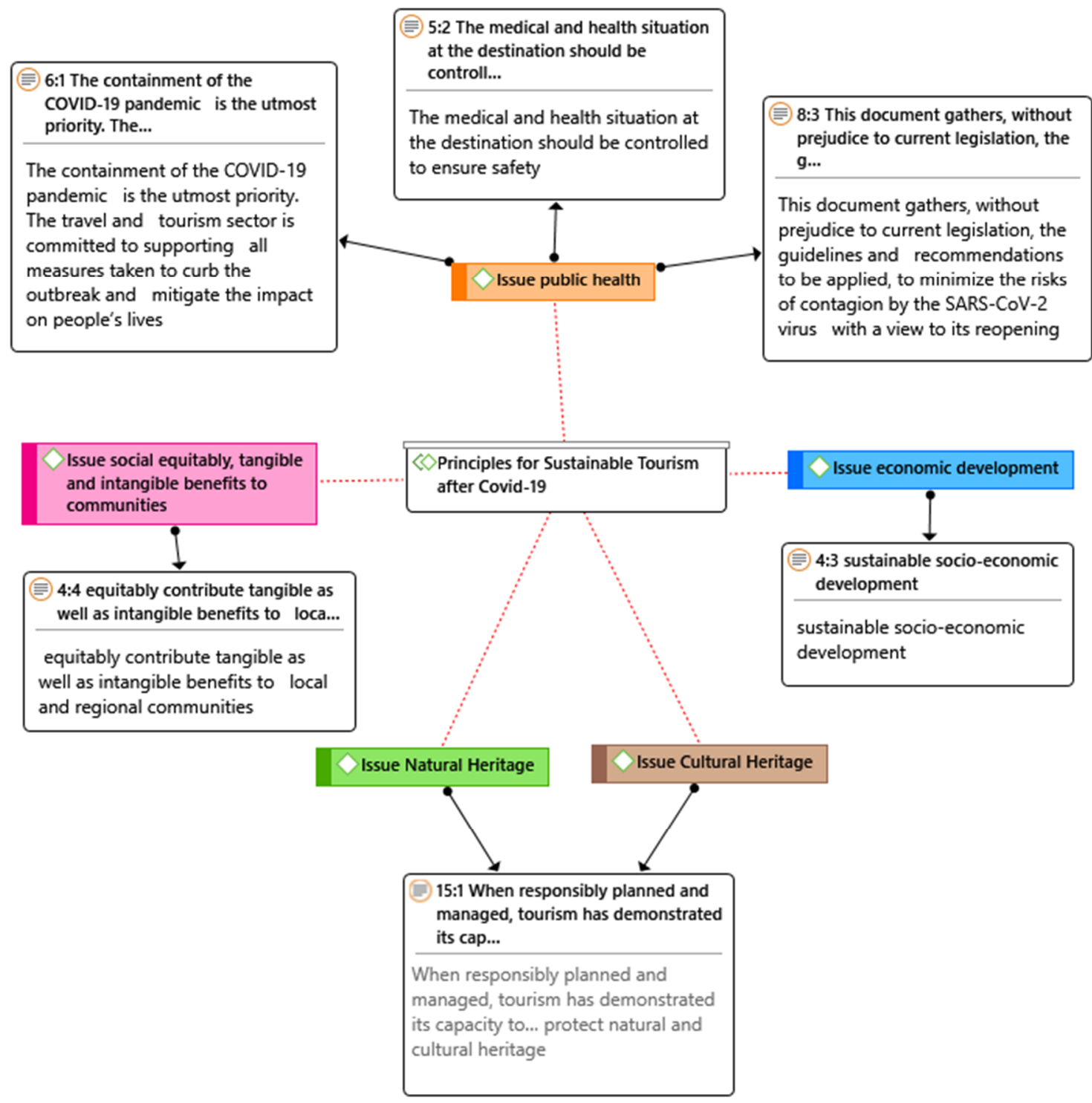

Figure 8. Visitor-management objectives according to the theory of sustainability and risk society for the post-COVID-19 era. Source: prepared by the authors.

We believe that the goal is not to apply a paradigm which is totally different from the paradigm of sustainable development for visitor management that has been applied so far, but to complement the classic paradigm with the new principle of public health. However, this entails dramatic changes in the classic paradigm, since the first requirement for visitor management was economic profitability, provided that the social and heritage requirements were not neglected-in fact, there were visitor capacity limitations to avoid damage to the environment. Now the principle of public health is showing to be the key principle, although it is contrary to the economic benefits considered from the pre-COVID-19 perspective. In summary, there is a change in the structure of the paradigm of sustainable development, as a new principle is introduced, and also the weight of the different issues is altered. Furthermore, this involves key aspects of the destination and visitor management, such as carrying capacity. In the past, the carrying capacity was established considering a certain balance between the three objectives pursued: economic profitability, social acceptance and cultural and natural 
heritage sustainability. Currently, carrying capacity is conditioned mainly by social distancing and public health. Moreover, new actors come into play (Table 5).

Table 5. Objectives and strategies pre- and post-COVID-19 according to the forms of power established for the management of visitors and decision-making actors. Source: prepared by the authors.

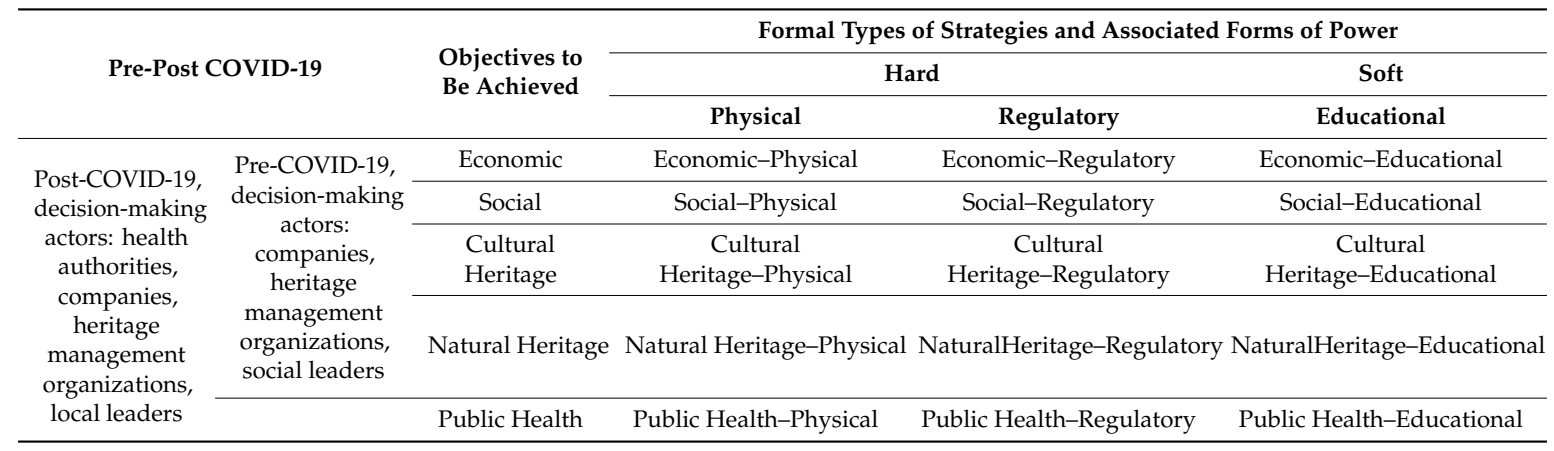

This change in the weight of the issues leads to confrontation between the health authorities of the countries-and the world — and the responsible actors in the area of tourism. Health authorities establish public health principles which often cause tourism companies to be unprofitable. The responsible actors in the area of tourism claim that the economic principle must be introduced as a priority [44], as often the resulting economic problem can cause more public health problems than the virus itself [45].

The whole visitor-management process is difficult and requires the implementation of a governance process. To this end, UNESCO refers to the need to use Destination Management Organizations (hereafter DMOs) techniques. In all events, the DMOs, though they take account of the interests of the different actors, must be based on some principle of authority so that the decisions for the benefit of sustainability are implemented, even when those decisions can be contrary to the interests of some stakeholders [46]. UNESCO states the need for this authority with the capacity to make decisions that contribute to sustainable alternatives:

"The authority and capacity to control or prevent Outstanding Universal Value (OUV) damaging activities-which often includes making tough, perhaps even counterintuitive, decisions and enforcing them-is crucial. Many of the most progressive World Heritage sites have offered businesses and communities dynamic and sustainable alternatives to activities that damage the site's values. However, they will also enforce protection when it is necessary" [1].

There are interests of different types of stakeholders, the classical ones (APSARA, UNESCO, local business owners, local civil society, international organizations which provide money and technical staff, countries, national policy, etc.) and now the new stakeholders-health authorities. In some instances, such interests may not be similar, but a decision must be made eventually. Thus, an institution is needed which, although it must have democratic behaviors with the different actors, can have the legitimized authority to determine, in some cases, those behaviors that are understandable and typical of a specific actor, but are not in line with the principles of sustainability, which must be pursued on grounds relating to the good of the resource and the community in the future.

The analysis of the principle of legitimized authority will be based on Suchman's [22] typology. The authority of experts, health organizations and DMOs responsible for tourism, as well as global organizations working for heritage sustainability, must be based on the principles of moral-procedural and cognitive legitimacy. 
Based on that authority, the DMOs must implement a series of visitor-management tactics. In the case of Angkor, we divided them into three main strategies: physical, regulatory, and educational. According to Nye [47], these three strategies can be grouped together in two large blocks. We can call them hard visitor-management strategies and soft visitor-management strategies [15], p. 89. Even if they are presented separately, these strategies must work together in a coordinated manner, as hard strategies alone, without the support of soft strategies, are not effective. The power whose enforcement is based entirely on brute force ends up being ineffective, as explained by Weber [48]. Soft power is essential so that hard power is unconsciously enforced in the long run.

Thus, we organized the strategies based on Kuo's [15] epistemological principles, as well as his view that hard strategies tend to be ineffective in the long-term, when they are implemented alone, as they rely only on restrictions. Hard strategies need the support of soft strategies, but care is necessary, as sometimes soft strategies can only be enforced if they are implemented the hard way. A good example of this is Phnom Bakheng, where we could observe the behavior of a young woman who began to eat. A person of the group warned her that she was not allowed to do that. She continued to do so until a passing keeper told her that she was not allowed to eat, and then she stopped. In other words, as long as visitors do not internalize the rules of behavior, hard strategies will still be necessary, as well as staff to ensure compliance, even if only dissuasively.

"Covid-19: Putting People First" [49] is the motto which best presents the need for health to be considered first when making decisions concerning COVID-19 and tourism. However, combined with the need to protect public health, there is also a need to protect the tourist sector, which provides employment and economic benefits. "We must be ready to act fast to save lives. But it also now also clear that we can also take decisive action to protect jobs and safeguard the many benefits tourism delivers, both for people and planet" [50].

According to the World Health Organization and the World Tourism Organization, this is the idea that should be conveyed to the different governments and to all organizations at different levels. Thus, a multi-sectoral cooperation (different stakeholders) and a multi-level cooperation (different levels of government) are both necessary. To this end, it is essential to implement regulations and controls at the local scale, regarding activities that do not contribute to achieving the stated objectives and, furthermore, are illegal.

Visitor management includes the enforcement of a power structured by the State, through multiple management organizations [51], regarding space, the objects of attraction, the bodies of visitors, their clothes and behavior [52], and their movements (where they can and cannot tread, what they can or cannot touch), how they relate to each other [53], how they move around, how they eat, and how they deal with the locals; as donations must be made to formal organizations controlled by the power established and legitimized for such purpose [54].

Studies on tourism, and specifically on visitor rules, are ultimately a moral issue [55]. Therefore, it is necessary to consider the different organizations which develop the studies, as well as the codes of conduct proposed by them. There is a possibility that they may "reinforce, conflict with, or complicate other moral layers within a particular setting. What values become authorized in such circumstances, and who benefits, how, and at whose expense? As the field of tourism studies takes the 'moral turn' $\ldots$, such lines of inquiry are increasingly relevant to understanding, critiquing, and envisioning the sustainability of tourism encounters" ([56], p. 1180).

In this case, APSARA indicates that the Angkor visitor code of conduct was developed "in cooperation with local communities, visitors, tour guides and restoration teams" [1]. This code derives from a previous process of analysis of the situation seeking to achieve the sustainability and longevity of Angkor which gave birth to the Angkor World Heritage Area Tourism Management Plan, 2012-2020. As summarized by Hang [57], different stakeholders were involved in the whole process, amongst which the following should be highlighted, according to UNESCO:

“A 'Tourism Industry Stakeholder Workshop' and a 'Community, Monks and NGO Workshop' were held in Siem Reap in March 2012. Together, all of the stakeholders involved provided 
feedback, drafts, and changes prior to the adoption of the final draft of the Tourism Management Plan (TMP) aiming to make the industry more sustainable and beneficial to the conservation of the World Heritage site, the local community, and tourism businesses within the destination" [1].

In summary, APSARA, UNESCO, WTO, WMF, International Coordinating Committee for the Safeguarding and Development of the Historic Site of Angkor (ICC-Angkor), local communities, business owners, monks, NGOs delivering assistance, and countries that collaborated in an inclusive way in the project that led to the visitor-management system in place, which is analyzed in this research.

However, with COVID-19, a new actor comes into play-the authorities responsible for protecting public health. Every document issued by the organizations responsible for tourism globally or domestically is based on that premise. Our objective, the weight given to it in the model, and the actors who must ensure that new visitor-management tactics are introduced are legitimized inside the system $[15,22]$.

The sustainability goals and the power structure are modified by the crisis of the system introduced by the COVID-19 pandemic. As long as the crisis situation caused by COVID-19 does not disappear, the most important goal is related to public health. The organizations having the critical power to decide on visitor-management strategies are no longer tourism authorities, but health authorities, which prevail over tourism authorities-globally, the World Health Organization [58], which calls for responsibility and coordination, but also the national health organizations, which, in the case of Cambodia, is acting jointly with the government, to avoid the spread of the disease, imposing very rigid conditions for visiting the country that are delivering good results, but are not to the liking of the specific actors of the tourist sector [48].

We can therefore say that the paradigm of sustainable development employed in recent years continues to be maintained. It led to a vast organizational activity and to the implementation of visitor-management tactics, and it is now combined with the paradigm of risk society with three redevelopments: (a) such organizational activity currently has a new key actor-health organizations and authorities-who makes basic decisions; (b) it is necessary to introduce a new sustainability goal related to risk society at the highest level - the risk for public health and the human species itself, which changed the way we behave and see the world; and (c) such a goal does come into conflict with other previous sustainability goals, prevails over them, and is considered first in order to establish economic, social-relation, and carrying-capacity criteria.

\section{Conclusions}

In these conclusions, we try to give an answer to the research questions and objectives established at the beginning of the study. The answer is given by the results presented based on the analysis of the data from Angkor collected through participant observation and the proposals of international bodies, as well as the experts responsible for the measures that must be taken in the sector for protection against the COVID-19 pandemic.

One relevant conclusion is that the objectives, strategies and tactics in place for visitor management in World Heritage destinations prior to COVID-19 can be adapted to the classic sustainable development goals (economic, social, cultural heritage, and natural heritage), combined with the strategies that we divided into three main types: physical, regulatory, and educational. The two first strategies can be considered as hard strategies, and the educational ones as soft strategies, but they complement each other. Within each objective, and combining them with the three types of strategies, different tactics can be identified. During the visit, visitors can clearly appreciate such tactics, which give them different directions regarding behavior and the significance of the visit. The authorities in charge of the management of the destination in the case of Angkor, in addition to the specific instructions for each location, developed a "Visitor Code of Conduct", which sets out the general recommendations that visitors must follow. In order to solve the overtourism problem and the potential problems for the destination, the authorities established a carrying capacity for specific locations which were the 
most overcrowded, with precise instructions for visitors regarding their behavior, the waiting time for access depending on their position in the line and the recommendations regarding behavior once they are inside.

In this research, we can conclude that with the outbreak of COVID-19 the destination went from having overtourism problems to a desert-like situation where there are no visitors and even traveler movement between countries is difficult, following the rules of the health authorities to prevent infection risks. According to researchers, the COVID-19 pandemic will mark a before and an after, a pre-COVID-19 era and a post-COVID-19 era, with a significant impact on tourism, visitor behavior and visitor management. To the classic sustainability goals, we can now add the goal related to public health and the prevention of the risk of spreading the pandemic. This must be based on regulatory, physical, and educational strategies. However, as stated in our specific initial objective regarding the weight of the new objective and the corresponding strategies and tactics, we must say that such strategies involve changes in the classic concept of carrying capacity, which now needs to be adapted to social distancing. This also involves changes in revenue, as the carrying capacity is lower than in the past.

The strategies in place are based on different forms of power. Some of them are mere recommendations for visitors in order to manage flows so that visitor behavior leads to satisfaction with the visit and has a positive impact on the sustainable development of the place. However, other strategies need to be based on obligatory legal regulations so that failure to comply with them is penalized. In other cases, the strategies are physical and consist of preventing access to a certain place, having to walk through an area without touching the objects or the carvings, being allowed to stop only for a limited time, having to dress appropriately for the culture of the destination, etc. Thus, two main types of strategies can be identified-those which must be enforced based on hard power (physical and regulatory strategies) and those based on soft power (educational strategies, which promote a certain behavior by educating visitors about values).

The emergence of new actors is confirmed, as well as the relevance of the question initially posed regarding whether new actors different from those which existed prior to COVID-19 come into play for visitor management with the pandemic. We must say that now the recommendations made by global and national health authorities and organizations must be considered. They dictate rules which directly affect visitor management and sometimes are not to the liking of the tourist sector, taking into account the interests of other actors, but also that health strategies prevail over the rest.

This study shows that the paradigm of sustainability employed in recent years to develop visitor-management strategies and tactics is still present, but has been modified in many ways. A new goal which was not explicitly present before COVID-19 is introduced-the goal related to health as part of a risk society which will be permanent in the future, even once the COVID-19 vaccines are available, as the world will have a different view of risks. Furthermore, such goal, with its corresponding strategies and tactics, must be supervised by health authorities and prevails over other classic actors responsible for visitor management. However, the changes go beyond a new goal and a new actor. They modify the classic structure of the paradigm of sustainability, as such a new goal will bring about alterations in classic strategies, prevailing over the rest and determining aspects as important as carrying capacity and the impact on key goals, such as economic profitability. Added to this are other aspects such as the online organization, which modifies the classic structure existing in destinations such as Angkor, where tickets were sold on-site and that involved a whole strategy regarding transport, reception infrastructure, ticket offices, workplaces, and checkpoints. In summary, the paradigm of sustainability is maintained, but with important changes. 
Supplementary Materials: The following are available online at http://www.mdpi.com/2071-1050/12/23/9929/s1, Table S1: ANGKOR PRE-POST COVID-19 (FIGURE 2). No. 2:82, 2:83, 2:84, 2:85, 2:86, 2:88, 2:89, 2:90, 2:92. Table S2: Visitor management tactics in Angkor (Appendix A Figures A2-A16). No. 2:1-2:81.

Author Contributions: Conceptualization, A.A.-S. and J.L.P.P.; methodology, A.A.-S. and J.L.P.P.; software, A.A.-S. and J.L.P.P.; validation, A.A.-S. and J.L.P.P.; formal analysis, A.A.-S. and J.L.P.P.; investigation, A.A.-S. and J.L.P.P.; resources, A.A.-S. and J.L.P.P.; data curation, A.A.-S. and J.L.P.P.; writing-original draft preparation, A.A.-S. and J.L.P.P.; writing-review and editing, A.A.-S. and J.L.P.P.; visualization, A.A.-S. and J.L.P.P.; supervision, A.A.-S. and J.L.P.P.; project administration, A.A.-S. and J.L.P.P.; funding acquisition, A.A.-S. and J.L.P.P. All authors have read and agreed to the published version of the manuscript.

Funding: This research received no external funding.

Acknowledgments: This study was funded by the Research Group on Territorial Studies at University of Coruña and the Department of Sociology at University of Granada.

Conflicts of Interest: The authors declare no conflict of interest.

\section{Appendix A}

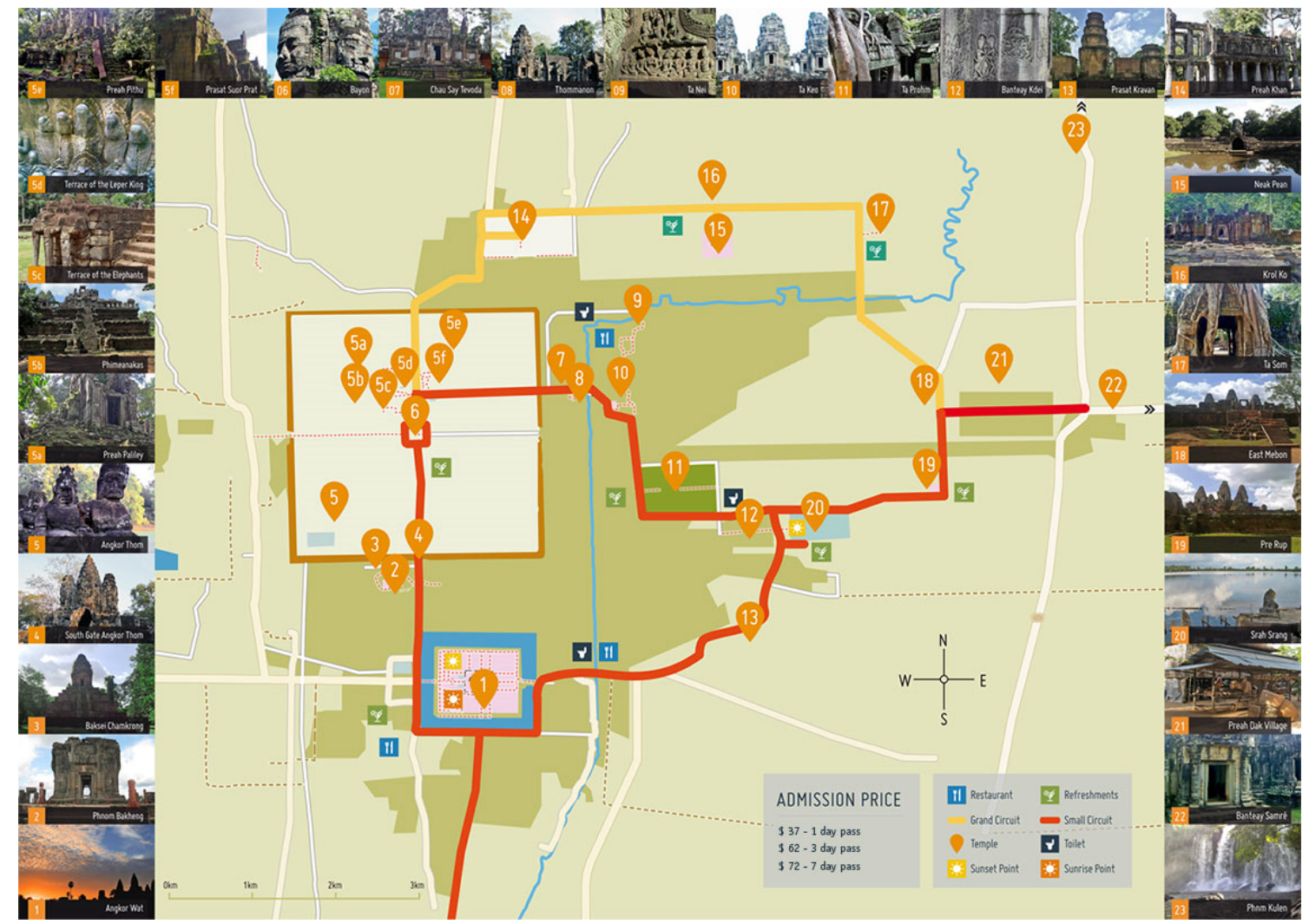

Figure A1. Angkor: small circuit and grand circuit. Source: https://www.visit-angkor.org/blog/2018/10/ 16/angkor-wat-angkor-park-info-prices-tips/\#conduct. 


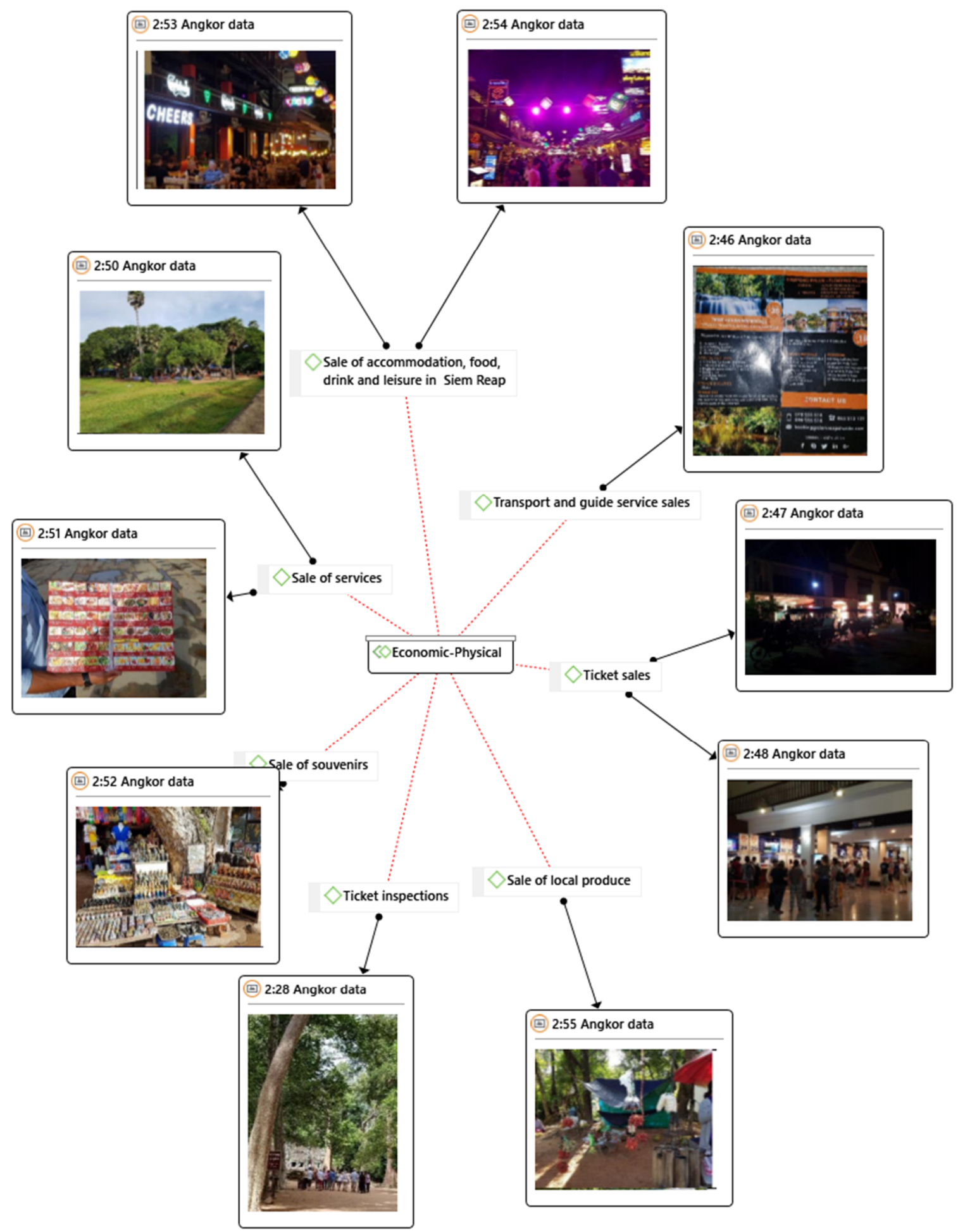

Figure A2. Economic objective tactics and physical strategy. Source: prepared by authors. 


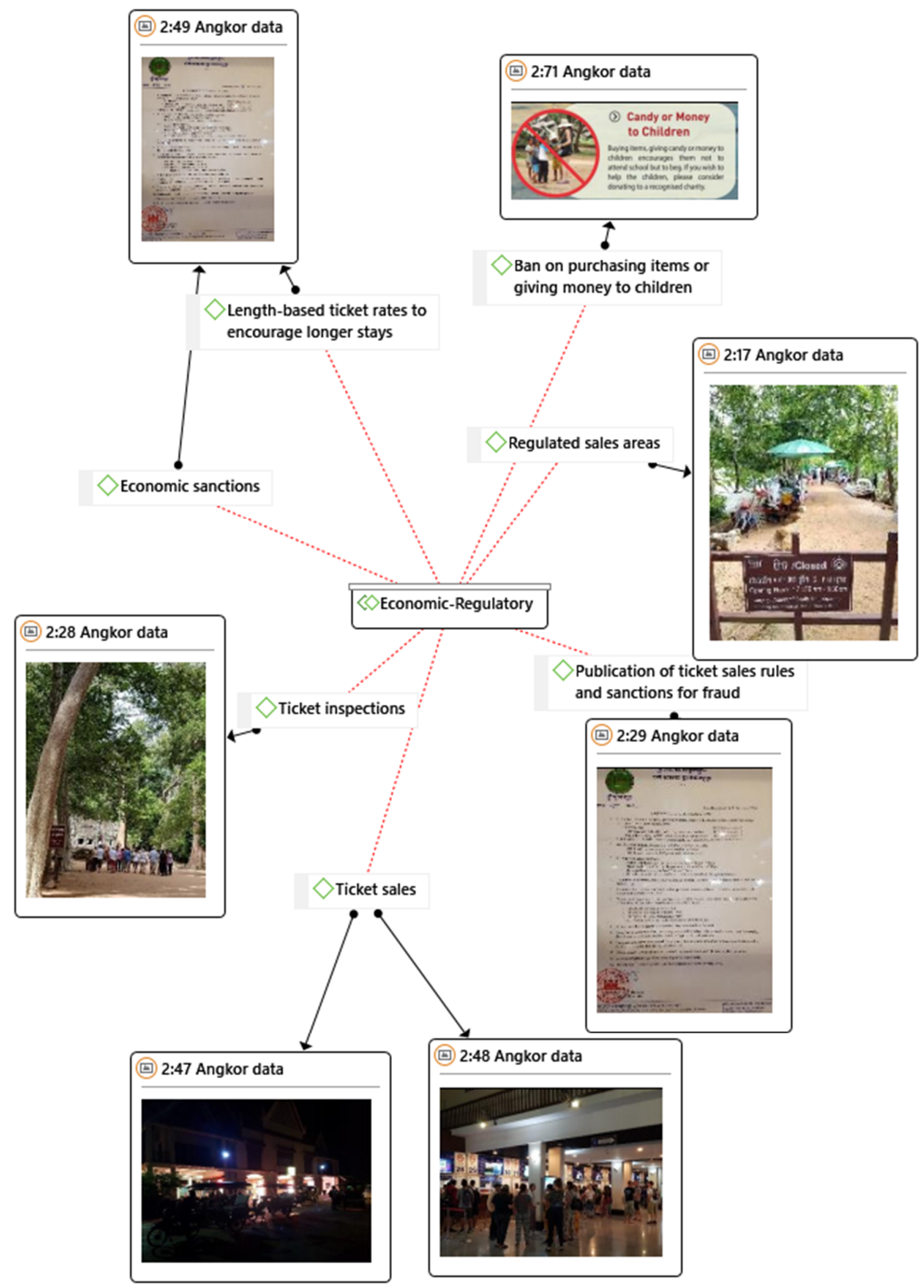

Figure A3. Economic objective tactics and regulatory strategy. Source: prepared by the authors. 


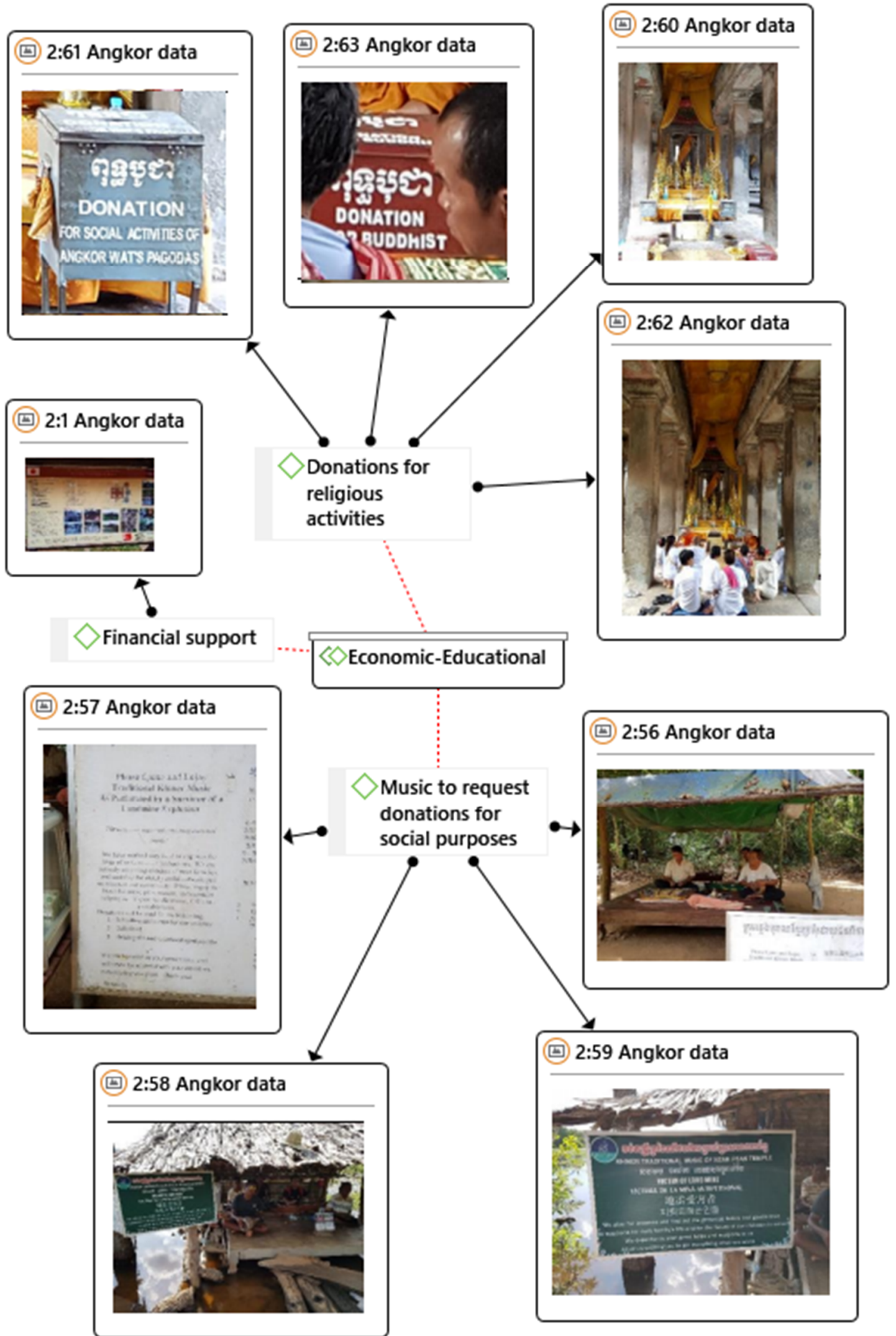

Figure A4. Economic objective tactics and educational strategy. Source: prepared by the authors. 


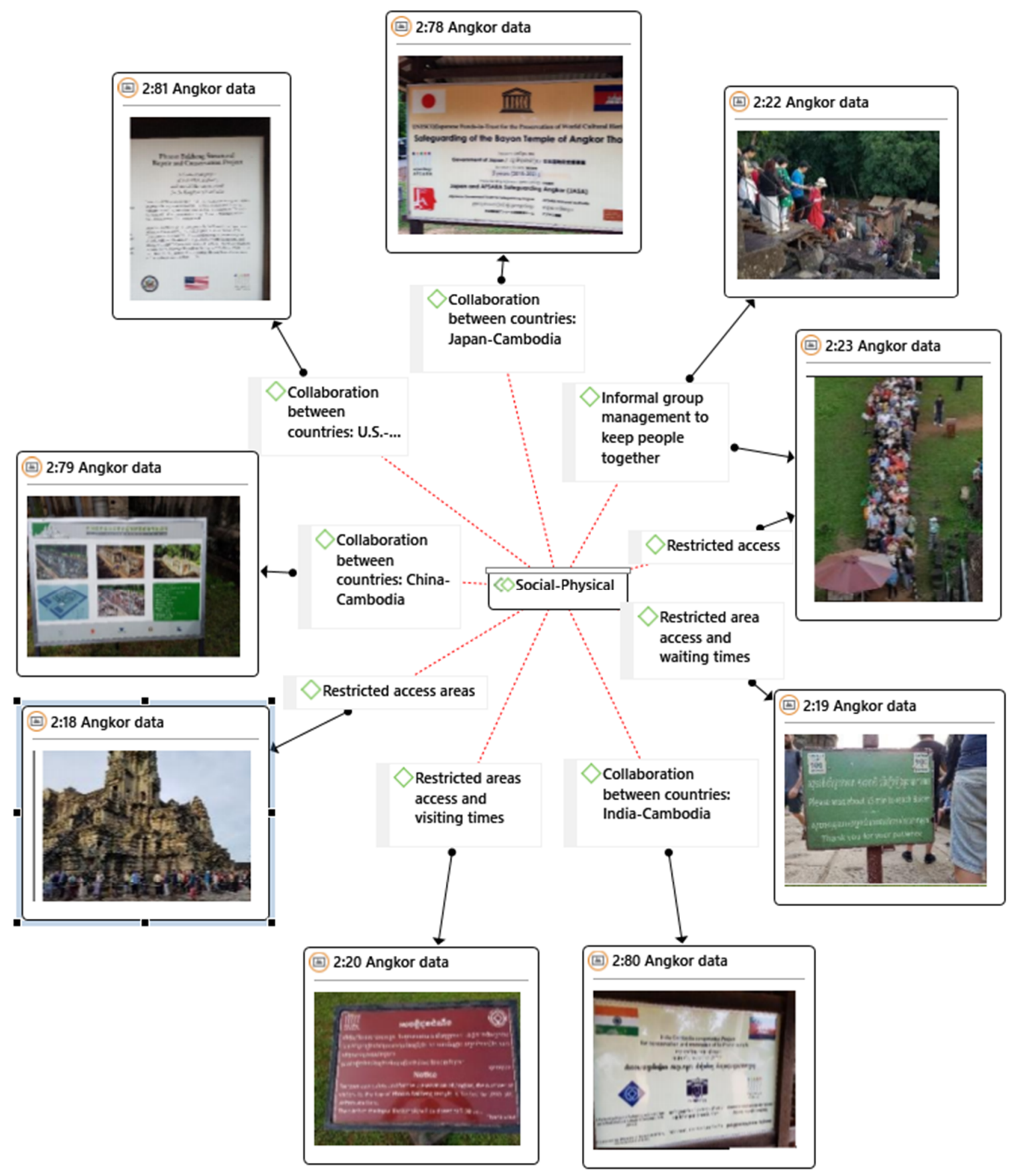

Figure A5. Social objective tactics and physical strategy. Source: prepared by the authors. 


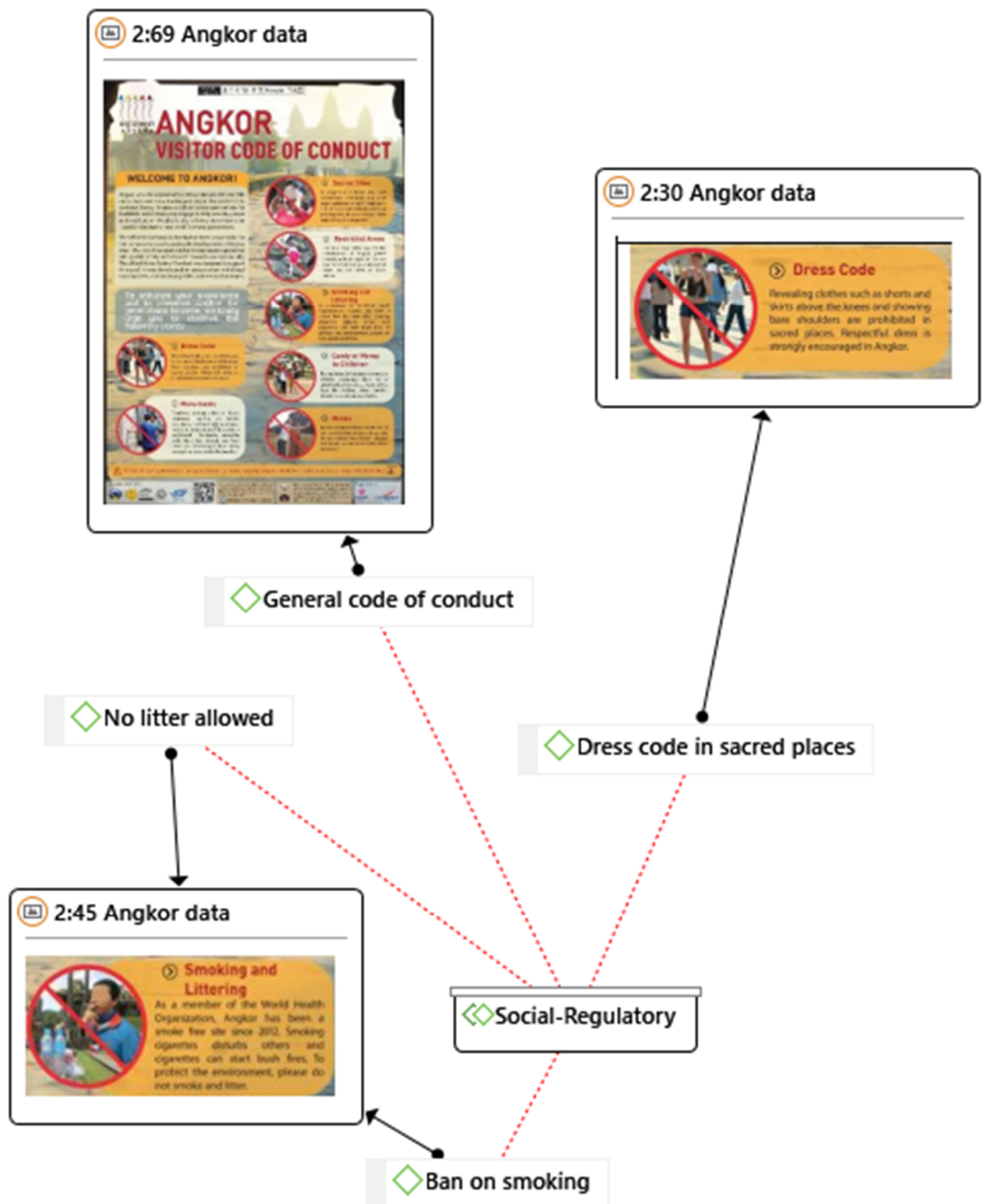

Figure A6. Social objective tactics and regulatory strategy. Source: prepared by the authors. 


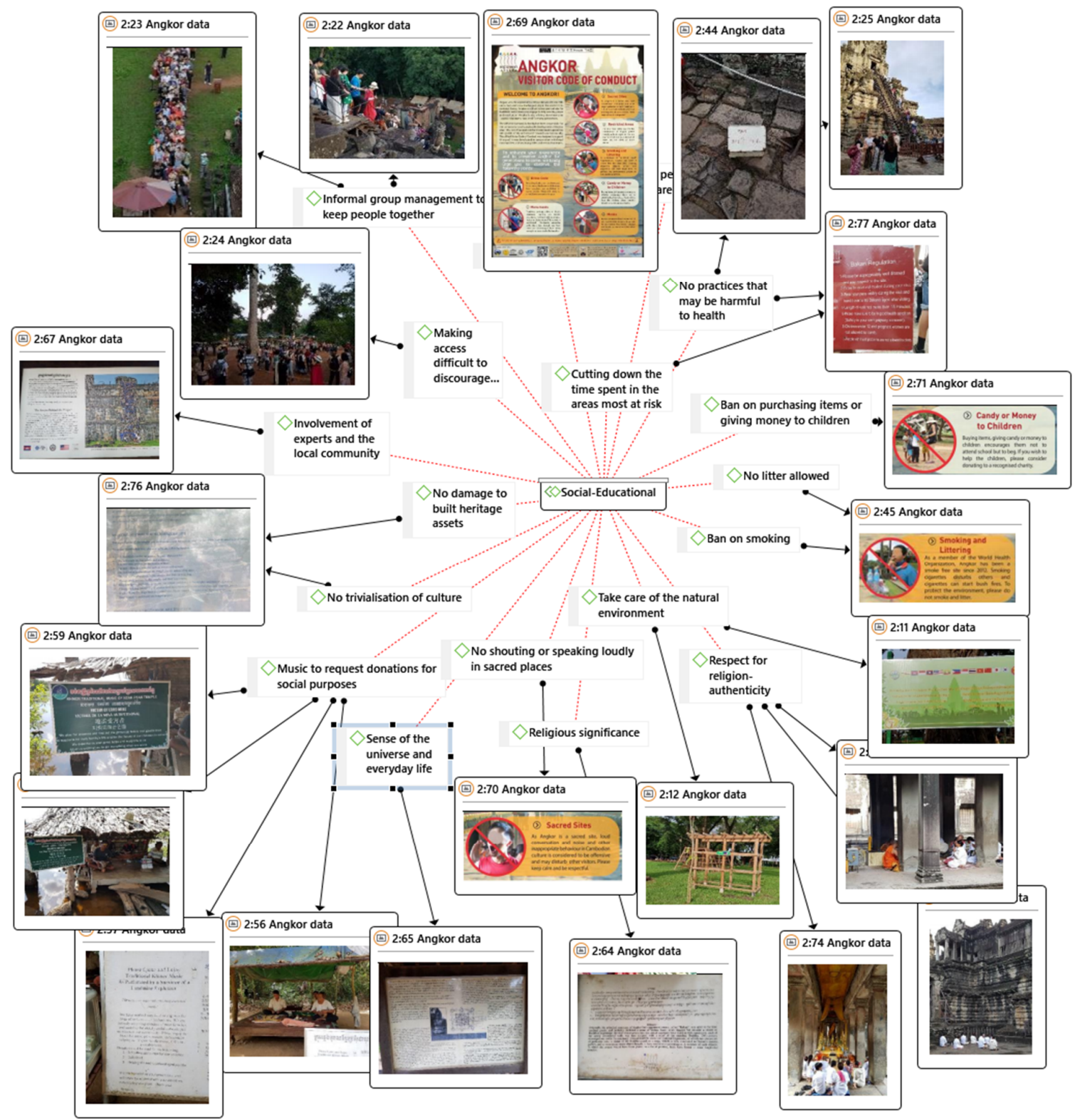

Figure A7. Social objective tactics and educational strategy. Source: prepared by the authors. 


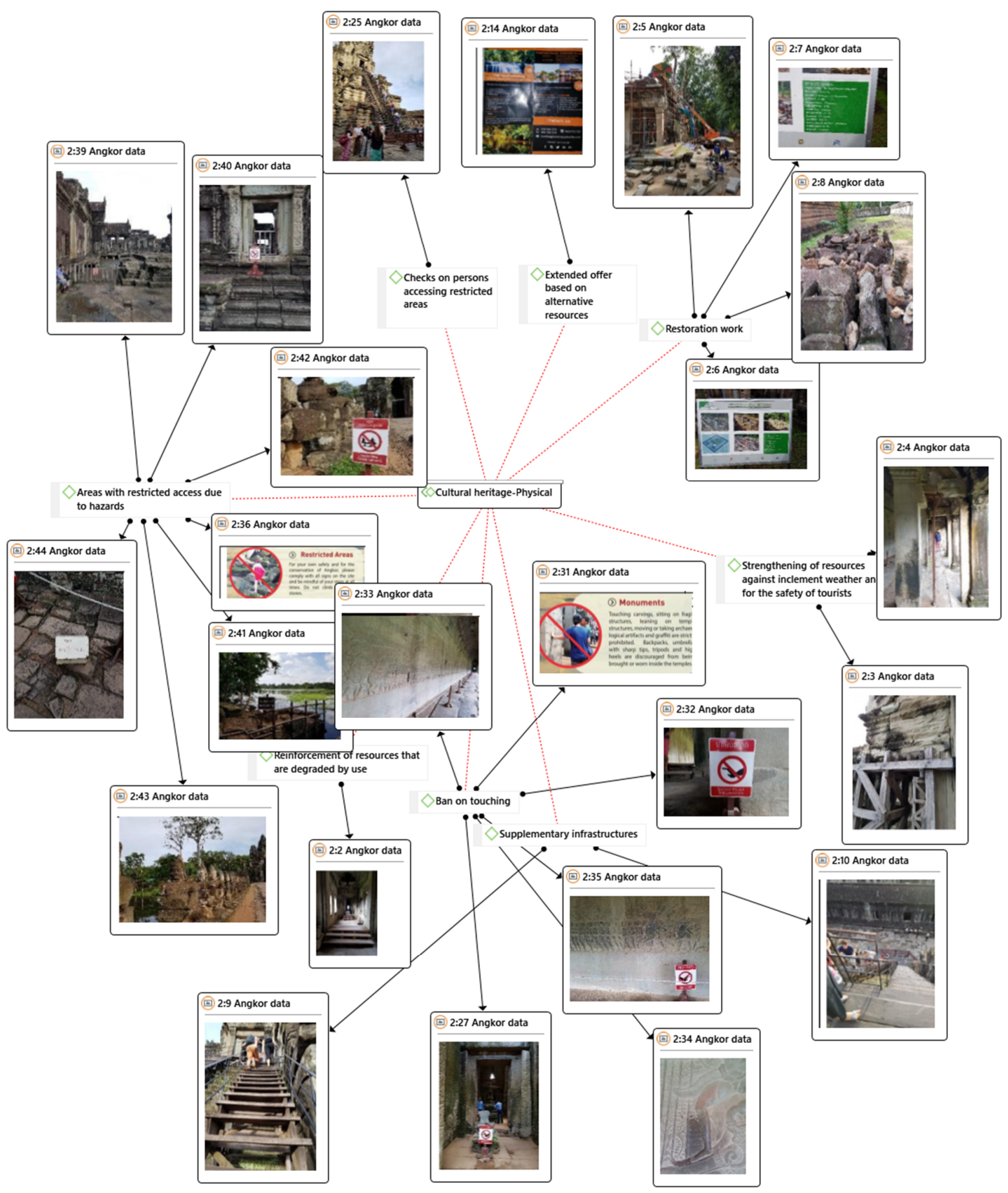

Figure A8. Culture heritage objective tactics and physical strategy. Source: prepared by the authors. 


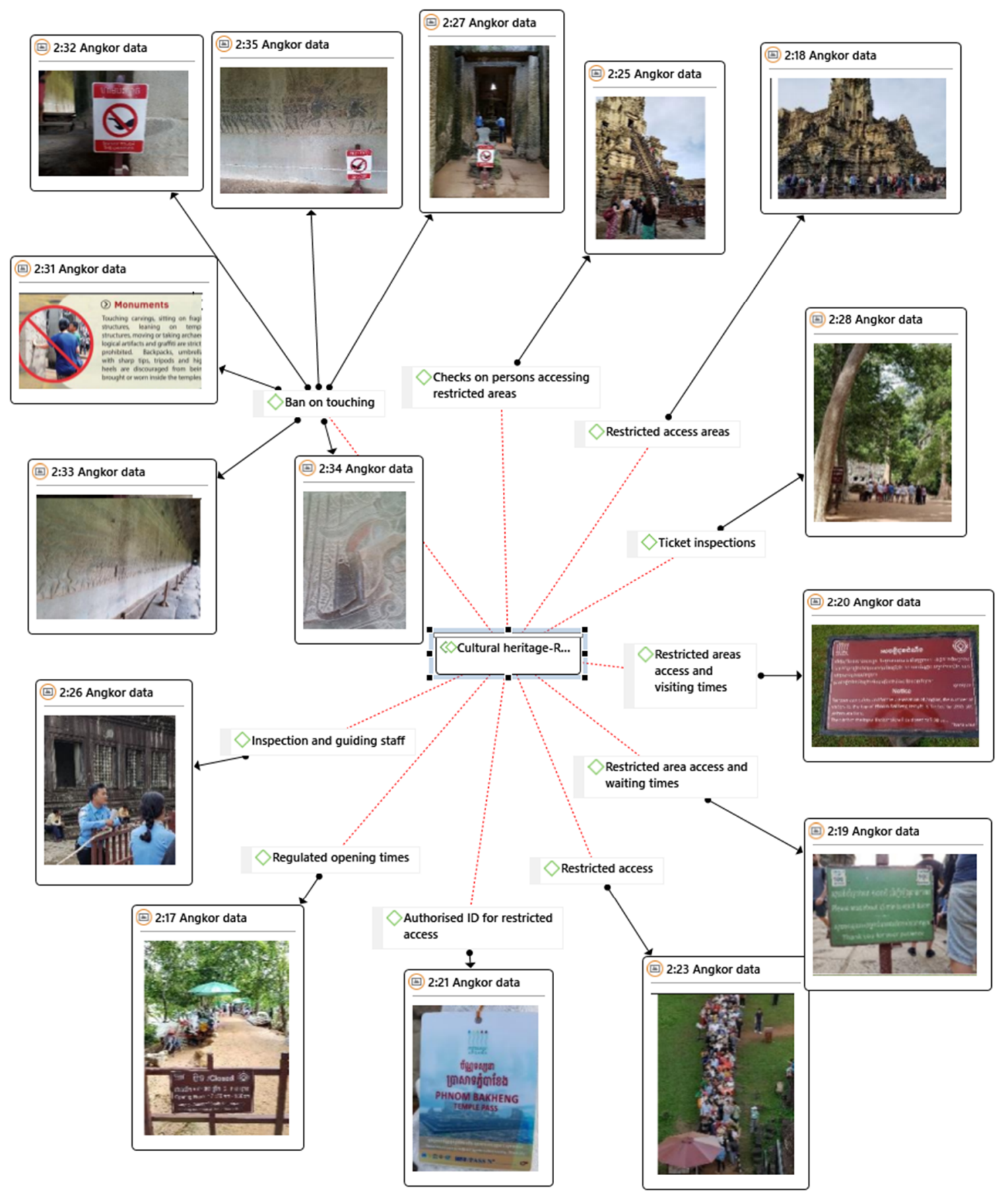

Figure A9. Culture heritage objective tactics and regulatory strategy. Source: prepared by the authors. 


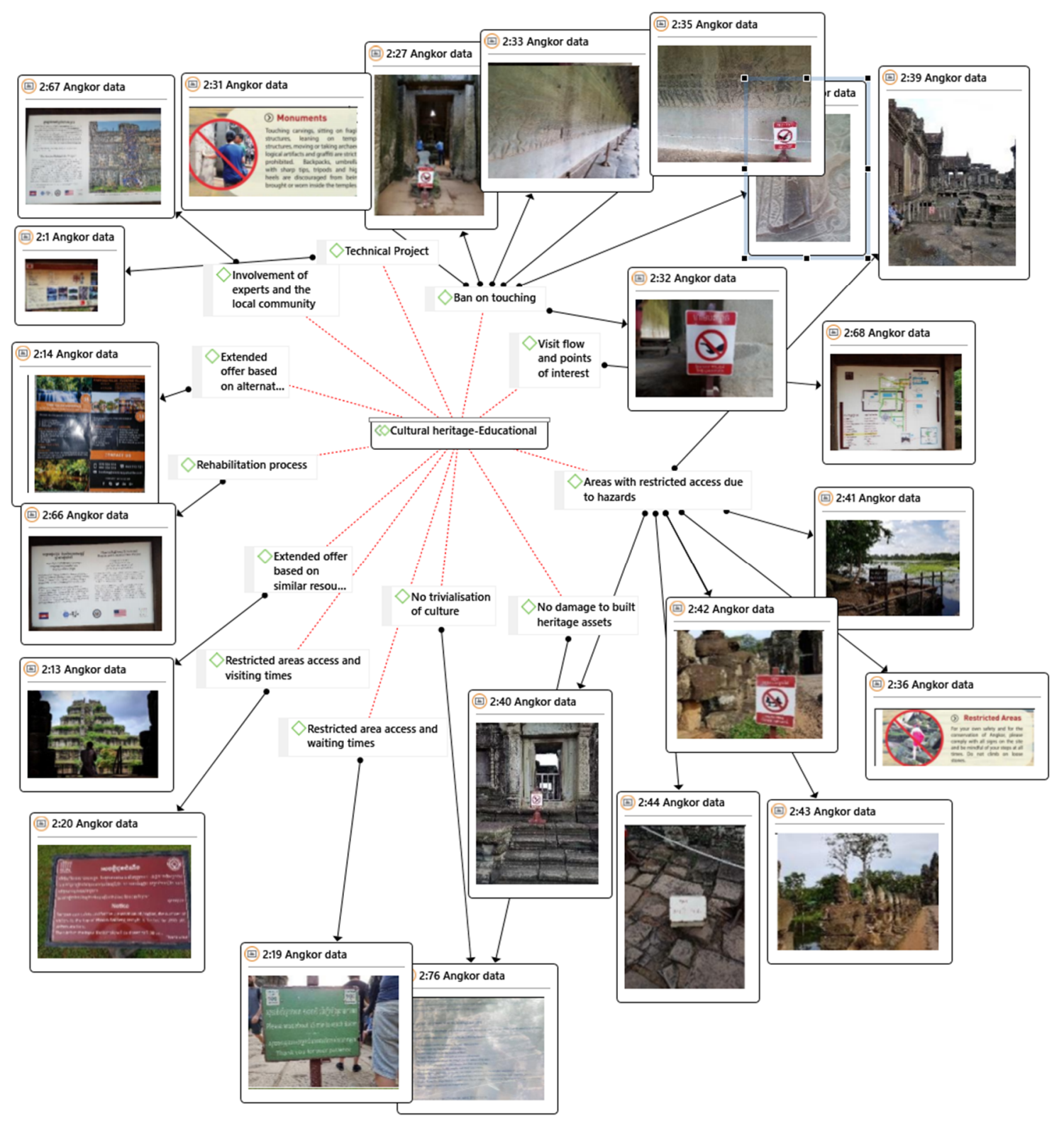

Figure A10. Culture heritage objective tactics and educational strategy. Source: prepared by the authors. 


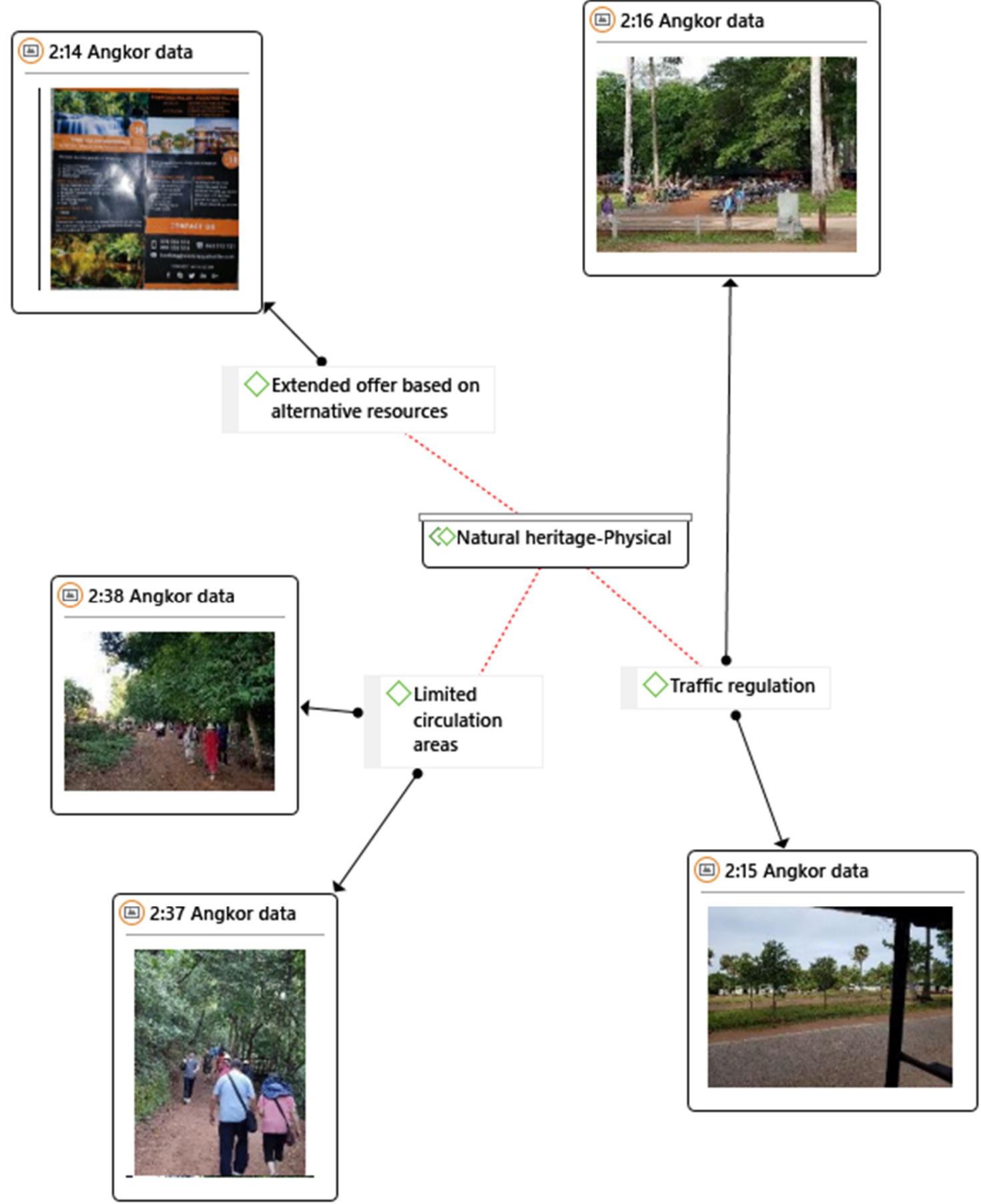

Figure A11. Natural heritage objective tactics and physical strategy. Source: prepared by the authors. 


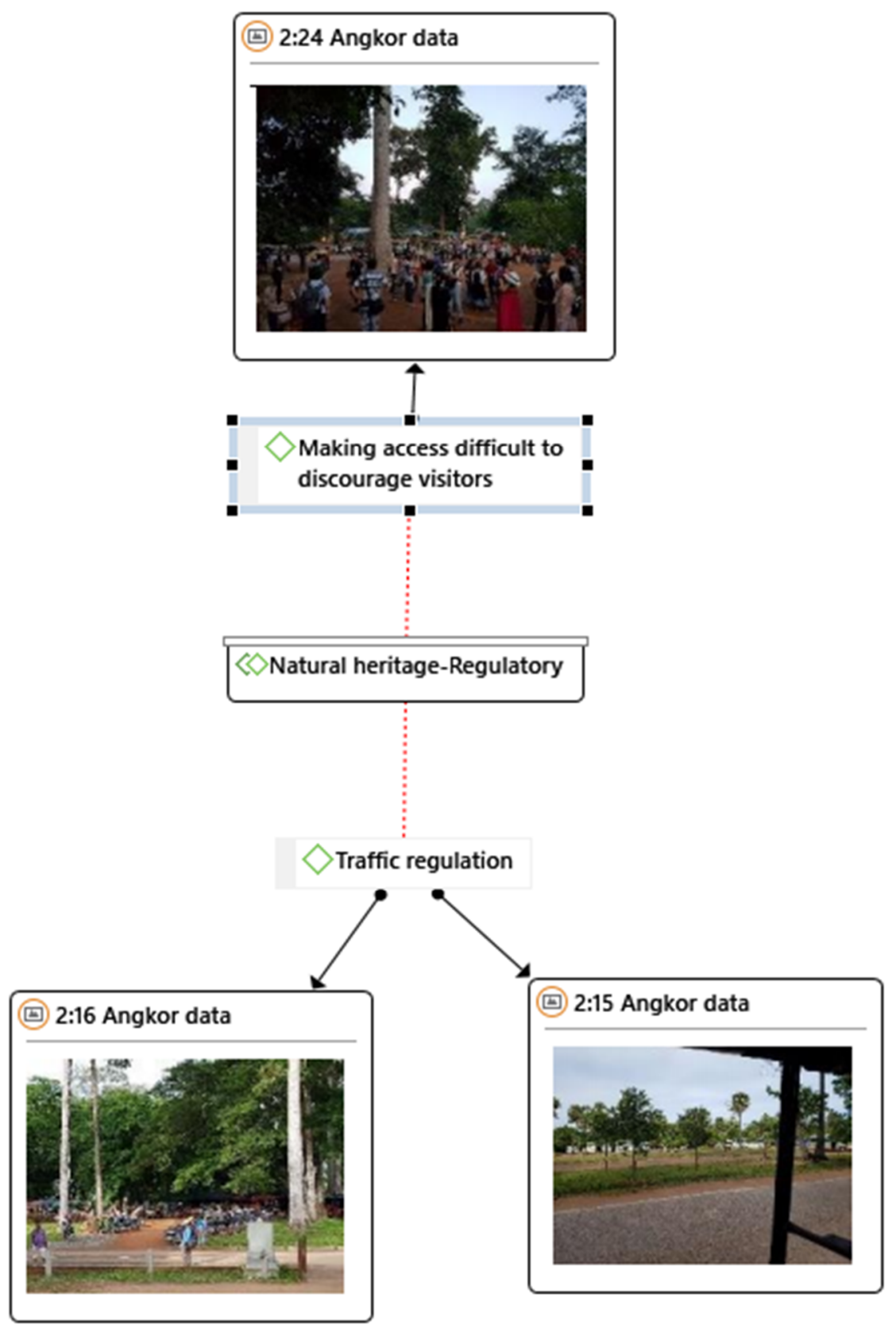

Figure A12. Culture heritage objective tactics and regulatory strategy. Source: prepared by the authors. 

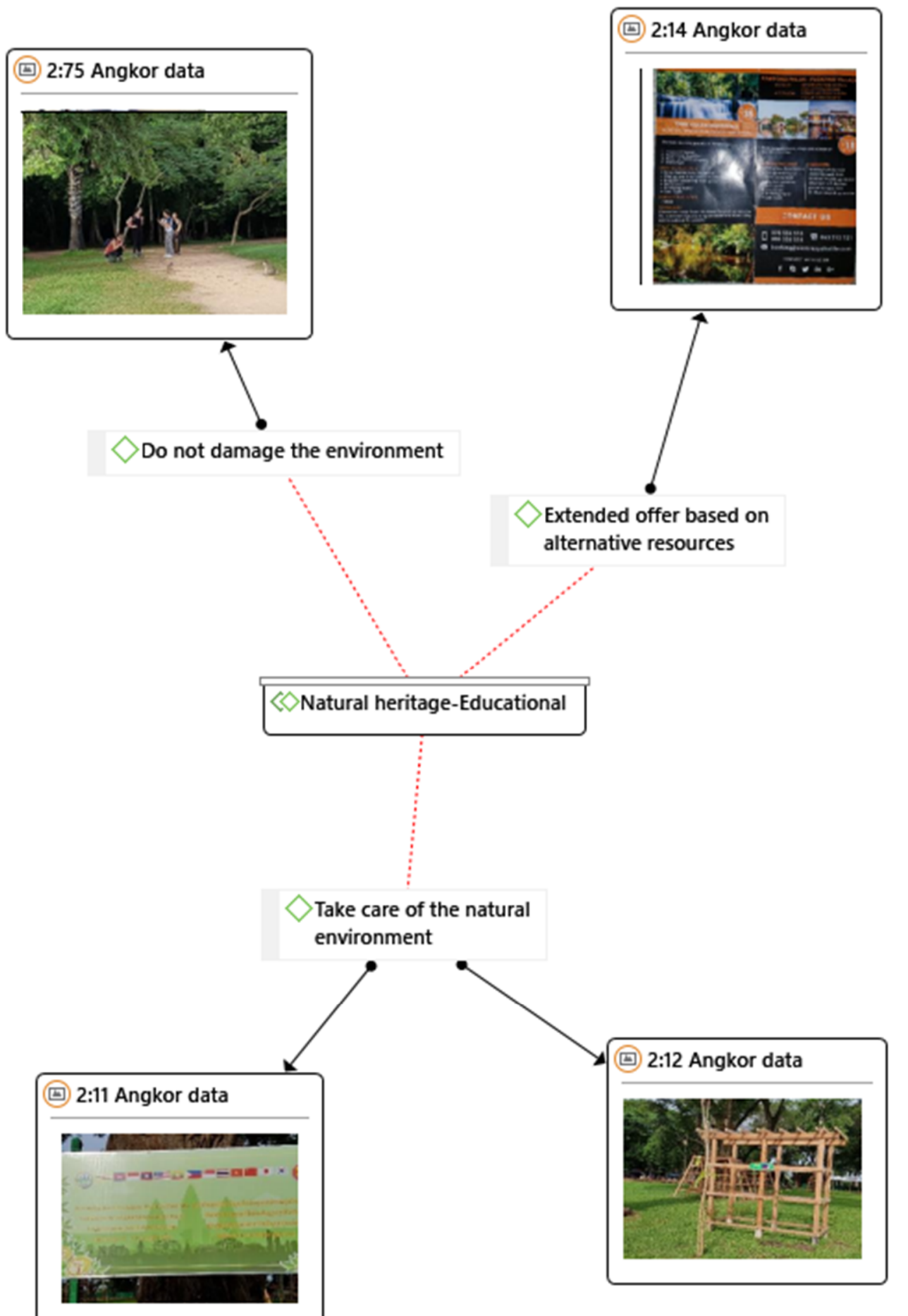

Figure A13. Culture heritage objective tactics and educational strategy. Source: prepared by the authors. 


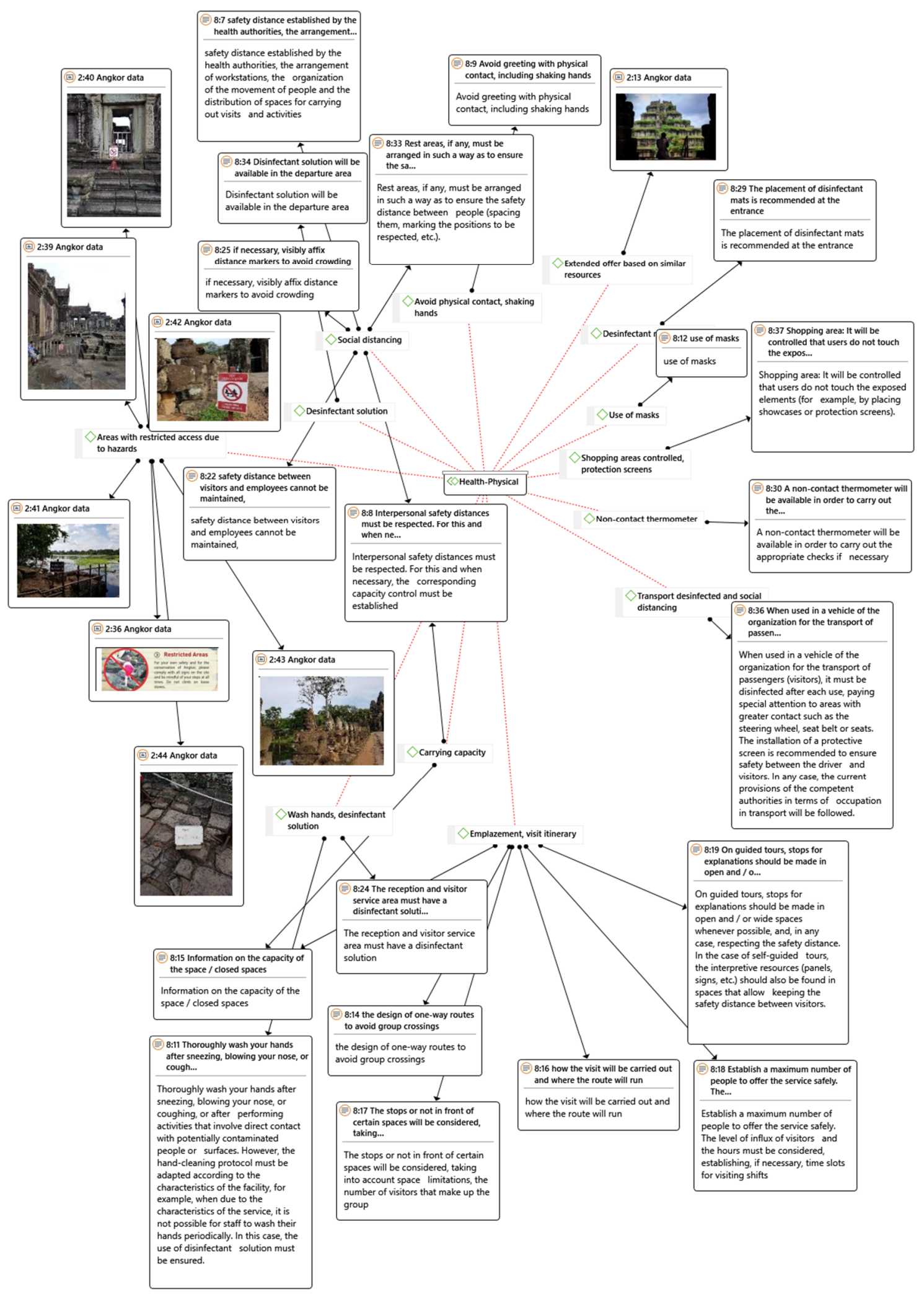

Figure A14. Public health objective tactics and physical strategy. Source: prepared by the authors. 


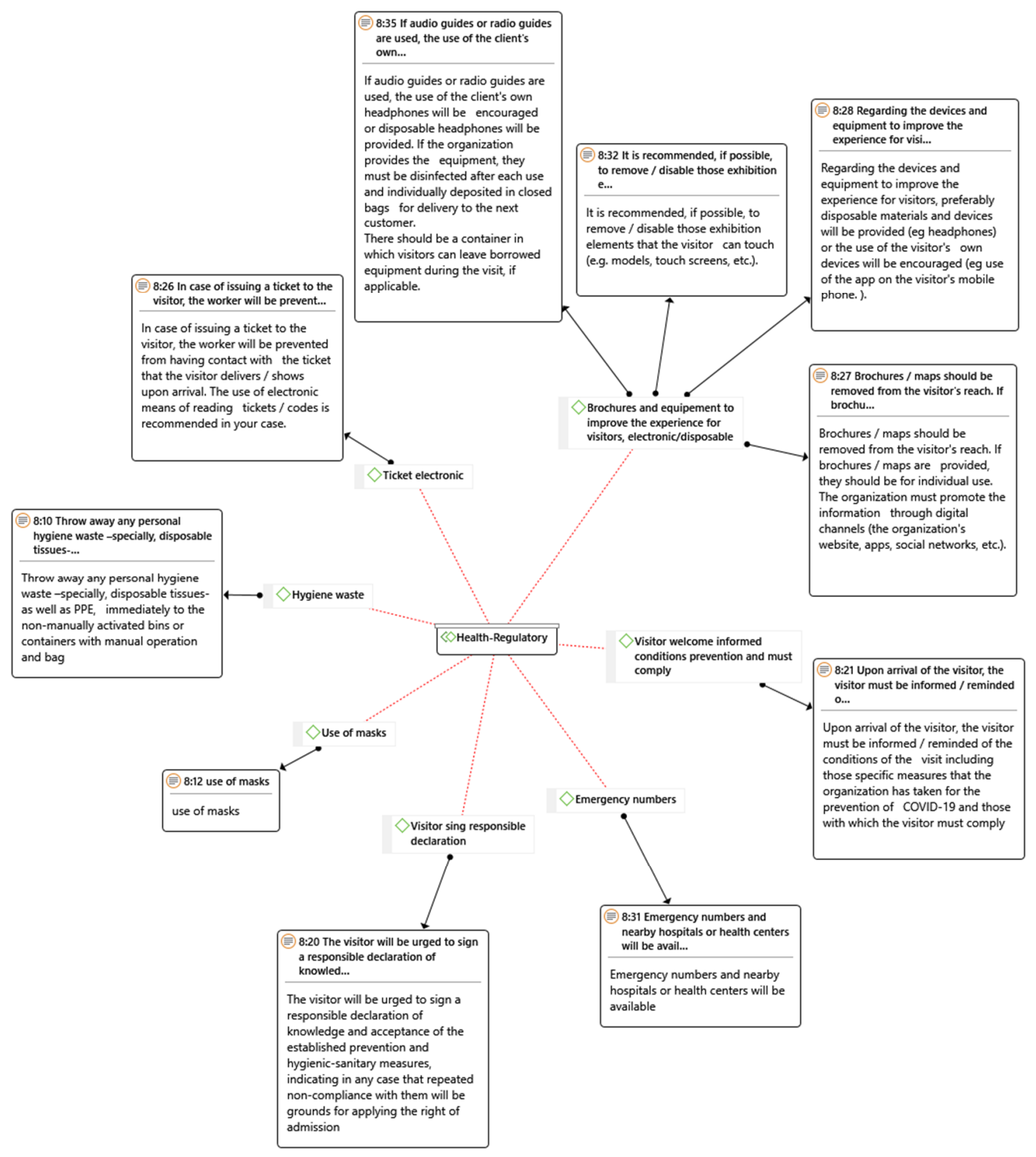

Figure A15. Culture heritage objective tactics and regulatory strategy. Source: prepared by the authors. 


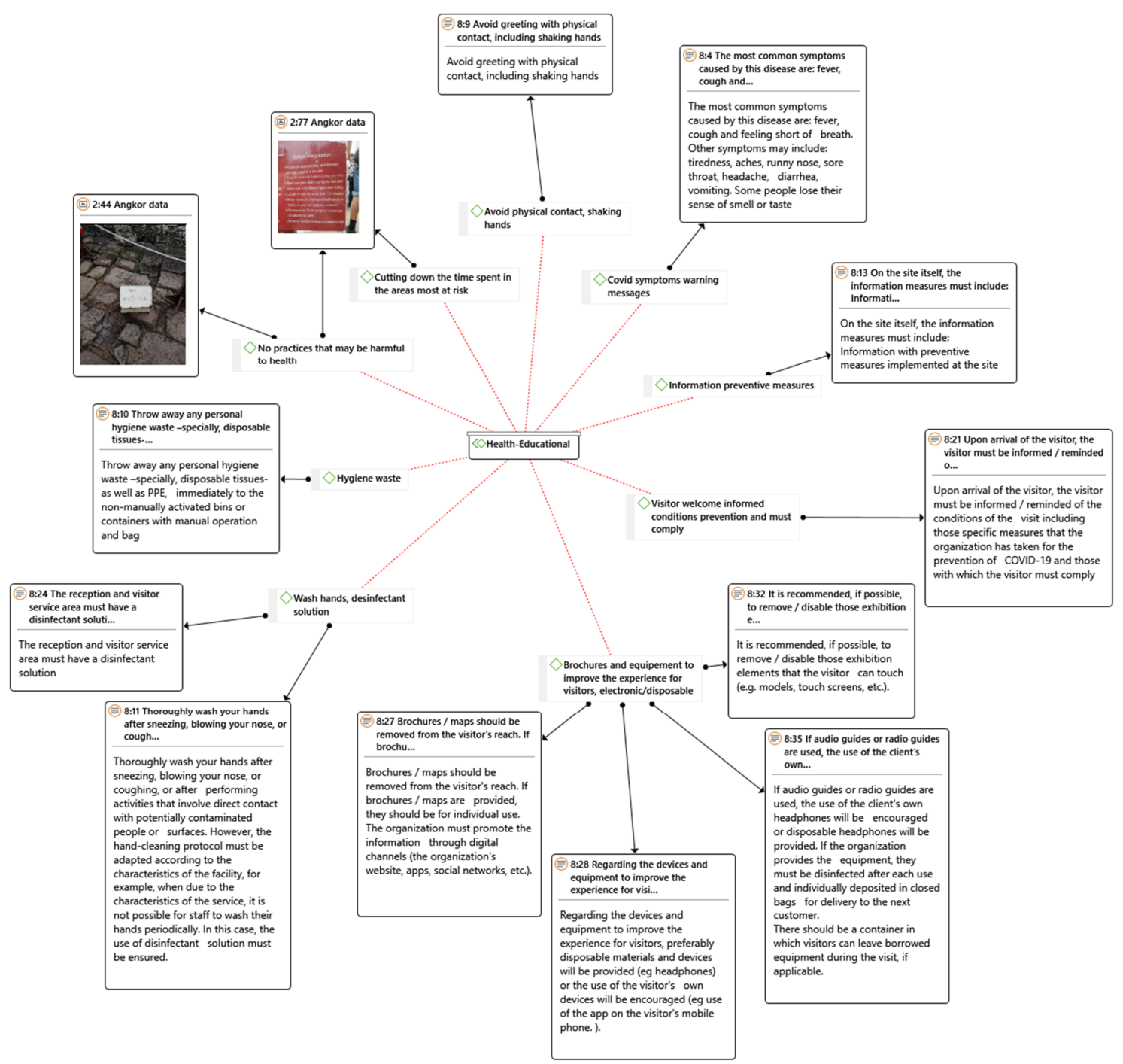

Figure A16. Culture heritage objective tactics and educational strategy. Source: prepared by the authors.

\section{References}

1. UNESCO. Angkor World Heritage Area. Tourism Management Plan. Available online: http://whc.unesco. org/document/134601 (accessed on 12 August 2020).

2. Shirvani Dastgerdi, A.; De Luca, G. Specifying the significance of historic sites in heritage planning. Conserv. Sci. Cult. Herit. 2018, 18, 29-39.

3. UNESCO. World Heritage Sustainable Tourism Online Toolkit. Available online: http://whc.unesco.org/ sustainabletourismtoolkit/ (accessed on 12 August 2020).

4. Olivié, I.; Gracia, M. ¿El fin de la globalización? Una reflexión sobre los efectos de la crisis del Covid-19 desde el Índice Elcano de Presencia Global. Real Instituto Elcano. Available online: http://www.realinstitutoelcano.org/wps/portal/rielcano_es/contenido?WCM_GLOBAL_CONTEXT= /elcano/elcano_es/zonas_es/ari43-2020-olivie-gracia-fin-de-la-globalizacion-reflexion-efectos-crisis-covid19-indice-ecano-de-presencia-global (accessed on 14 April 2020).

5. Brouder, P. Reset redux: Possible evolutionary pathways towards the transformation of tourism in a COVID-19 world. Tour. Geogr. 2020, 22, 1-7. [CrossRef]

6. Kuhn, T.S. La Estructura De Las Revoluciones Científicas; Fondo de cultura económica: Ciudad de Mexico, Mexico, 1971.

7. Beck, U. Risk Society. Towards a New Modernit; Sage Publications: London, UK, 1992. 
8. D'Amore, L. Guidelines to planning in harmony with the host community. In Tourism in Canada: Selected Issues and Options; Murphy, P.E., Ed.; University of Victoria: Victoria, BC, Canada, 1983; pp. 135-159.

9. Ashley, C.; Roe, D. Enhancing Community Involvement in Wildlife Tourism: Issues and Challenges; IIED Wildlife and Development Series: London, UK, 1998.

10. Tosun, C. Towards a Typology of Community Participation in the Tourism Development Process. Anatolia 1999, 10, 113-134. [CrossRef]

11. World Tourism Organization. Sustainable development of ecotourism. A Compilation of Good Practices. 2001. Available online: https://www.e-unwto.org/doi/epdf/10.18111/9789284404780 (accessed on 13 November 2020).

12. UNWTO; OOAS. Tourism and the Sustainable Development Goals_Good Practices in the Americas; UNWTO: Madrid, Spain, 2018.

13. De Luca, G.; Dastgerdi, A.S.; Francini, C.; Liberatore, G. Sustainable Cultural Heritage Planning and Management of Overtourism in Art Cities: Lessons from Atlas World Heritage. Sustainability 2020, 12, 3929. [CrossRef]

14. Enseñat-Soberanis, F.; Frausto-Martínez, O.; Gándara-Vázquez, M. A visitor flow management process for touristified archaeological sites. J. Herit. Tour. 2018, 14, 340-357. [CrossRef]

15. Albrecht, J.N. Introduction to Visitor Management in Tourism Destinations. In Visitor Management in Tourism Destinations; CABI Publishing: Wallingford, UK, 2017.

16. Kuo, I.L. The effectiveness of environmental interpretation at resource-Sensitive tourism destinations. Int. J. Tour. Res. 2002, 4, 87-101. [CrossRef]

17. Orams, M.B. A conceptual model of tourist-wildlife interaction: The case for education as a management strategy. Aust. Geogr. 1996, 27, 39-51. [CrossRef]

18. Eagles, P.; McCool, S.; Haynes, C. Sustainable Tourism in Protected Areas: Guidelines for Planning and Management, 7 Tools for Visitor Management; World Commision on Protected Areas (WCPA), The World Conservation Union (IUCN): Cambridge, UK, 2002. Available online: http://www.unep.fr/shared/publications/other/3084/ BP8-7.pdf (accessed on 1 October 2019).

19. Mason, P. Visitor management in protected areas: From 'hard' to 'soft' approaches? Curr. Issues Tour. 2005, 8, 181-194. [CrossRef]

20. Manning, R.E.; Anderson, L.E. Managing Outdoors Recreation: Case Studies in the National Parks; CABI Publishing: Wallingford, UK, 2018.

21. Elhalem, A.; Motaal, D.; Ebied, A. Archaeological Replica Models: A New Visitor Management Technique to Sustain the Heritage Sites. Int. J. Tour. Hosp. Manag. 2019, 3, 14-35.

22. Suchman, M.C. Managing legitimacy: Strategic and institutional approaches. Acad. Manag. Rev. 2015, 20, 571-610. [CrossRef]

23. Beirman, D. Restoring tourism destinations in crisis: A strategic marketing approach. In Riding the Wave of Tourism and Hospitality Research; Braithwaite, R.L., Braithwaite, R.W., Eds.; Southern Cross University: Lismore, Australia, 2003; pp. 1146-1150. Available online: https://search.informit.com.au/documentSummary; dn= 844199323753492;res=IELIAC (accessed on 12 June 2020).

24. Prideaux, B.; Laws, E.; Faulkner, B. Events in Indonesia: Exploring the limits to formal tourism trends forecasting methods in complex crisis situations. Tour. Manag. 2003, 24, 475-487. [CrossRef]

25. Mair, J.; Ritchie, B.W.; Walters, G. Towards a research agenda for post-disaster and post-crisis recovery strategies for tourist destinations: A narrative review. Curr. Issues Tour. 2016, 19, 1-26. [CrossRef]

26. Mao, C.; Ding, C.G.; Lee, H. Post-SARS tourist arrival recovery patterns: An analysis based on a catastrophe theory. Tour. Manag. 2010, 31, 855-861. [CrossRef] [PubMed]

27. Ruan, W.; Li, Y.; Liu, C.S. Measuring Tourism Risk Impacts on Destination Image. Sustainability 2017, 9, 1501. [CrossRef]

28. Gellert-De Pinto, G.I. El cambio de paradigma: De la atención de desastres a la gestión del riesgo. Bol. Cient. Sapiens Res. 2012, 2, 13-17.

29. Saveriades, A. Establishing the social tourism carrying capacity for the tourist resorts of the east coast of the Republic of Cyprus. Tour. Manag. 2000, 21, 147-156. [CrossRef]

30. McCool, S.F.; Lime, D.W. Tourism Carrying Capacity: Tempting Fantasy or Useful Reality? J. Sustain. Tour. 2001, 9, 372-388. [CrossRef]

31. O'Reilly, A.M. Tourism Carrying Capacity: Concept and Issues. Travel Manag. 1987, 7, 254-258. [CrossRef] 
32. Martin, B.S.; Uysal, M. An examination of the relationship between carrying capacity and the tourism lifecycle: Management and policy implications. J. Environ. Manag. 1990, 31, 327-333. [CrossRef]

33. Brown, K.; Turner, R.K.; Hameed, H.; Bateman, I.A.N. Environmental carrying capacity and tourism development in the Maldives and Nepal. Environ. Conserv. 1997, 24, 316-325. [CrossRef]

34. Simón, F.J.G.; Narangajavana, Y.; Marqués, D.P. Carrying capacity in the tourism industry: A case study of Hengistbury Head. Tour. Manag. 2004, 25, 275-283. [CrossRef]

35. Salerno, F.; Viviano, G.; Manfredi, E.C.; Caroli, P.; Thakuri, S.; Tartari, G. Multiple Carrying Capacities from a management-oriented perspective to operationalize sustainable tourism in protected areas. J. Environ. Manag. 2013, 128, 116-125. [CrossRef] [PubMed]

36. Muler-Gonzalez, V.; Coromina, L.; Galí, N. Overtourism: Residents' perceptions of tourism impact as an indicator of resident social carrying capacity-case study of a Spanish heritage town. Tour. Rev. 2018, 73, 277-296. [CrossRef]

37. Mexa, A.; Coccossis, H. Tourism Carying Capacity: A Theoretical Overview. In The Challenge of Tourism Carrying Capacity Assessment: Theory and Practice; Routledge: New York, NY, USA, 2016; pp. 37-54.

38. Coccossis, H.; Mexa, A.; Collovini, A.; Parpairis, A.; Konstandoglou, M. Defining, Measuring and Evaluating Carrying Capacity in European Tourism Destinations; University of the Aegean, Greece, Environmental Planning Laboratory: Athens, Greece, 2002.

39. Yunfei, Q. Establishing a monitoring and warning system and tourism impact analysis and management for world cultural heritage in China. In Visitor Management and Carrying Capacity at World Heritage Sites in China; Agnew, N., Demas, M., Eds.; The Getty Conservation Institute: Jiuquan, China, 2013; pp. 29-34.

40. Guo, W.; Chung, S. Remarking Tourism Carrying Capacity Frameworks for Geoparks. In Proceedings of the 4th International Conference on Advances in Social Science, Humanities, and Management, Guangzhou, China, 24-25 December 2016.

41. Delanghe, P.; Peou, H.; Lloyd, G.; Mackay, R.; Sullivan, S. Tourism and Development: Angkor's Away; ICOMOS: Paris, France, 2008. Available online: http://openarchive.icomos.org/1211/1/III-1-Article4_Delanghe_Peou_ Lloyd_Mackay_Sullivan.pdf (accessed on 10 June 2020).

42. Strauss, A.; Corbin, J.M. Grounded Theory Methodology. Handbook of Qualitative Research; Sage: Newbury Park, CA, USA, 1994; pp. 273-285.

43. Strauss, A.; Corbin, J.M. Grounded Theory in Practice; Sage: Newbury Park, CA, USA, 1997.

44. Ratcliffe, R. Cambodia Tourism Chefs Call for End to Covid-19 Healthcare and Funeral Deposit. The Guardian. Available online: https://www.theguardian.com/world/2020/jun/25/cambodia-tourism-chiefs-call-for-end-tocovid-19-healthcare-and-funeral-deposit (accessed on 9 August 2020).

45. Buheji, M.; da Cunha, K.C.; Beka, G.; Mavrić, B.; De Souza, Y.L.; da Costa Silva, S.S.; Yein, T.C. The Extent of COVID-19 Pandemic Socio-Economic Impact on Global Poverty. A Global Integrative Multidisciplinary Review. Am. J. Econ. 2020, 10, 213-224. [CrossRef]

46. Byrd, E.T. Stakeholders in sustainable tourism development and their roles: Applying stakeholder theory to sustainable tourism development. Tour. Rev. 2007, 62, 6-13. [CrossRef]

47. Nye, J.S. Soft power. Foreign Policy 1990, 80, 153-171. [CrossRef]

48. Weber, M. Economy and Society: An Outline of Interpretive Sociology; University of California Press: Berkeley, CA, USA, 1978.

49. UNWTO. Covid-19: Putting People First. Available online: https://www.unwto.org/tourism-covid-19 (accessed on 20 November 2020).

50. UNWTO. UN Policy Brief on Tourism and COVID 19. Available online: https://webunwto.s3.eu-west-1. amazonaws.com/s3fs-public/2020-08/200828-sg-statement-en.pdf (accessed on 20 November 2020).

51. Velasco, M. Entre el poder y la racionalidad: Gobierno del turismo, política turística, planificación turística y gestión pública del turismo. PASOS Rev. Tur. Patrim. Cult. 2016, 14, 577-594. [CrossRef]

52. Guerra-Manzo, E. El problema del poder en la obra de Michel Foucault y Norbert Elias. Estud. Sociol. 1999, 17, 95-120.

53. Cheong, S.M.; Miller, M.L. Power and tourism: A Foucauldian observation. Ann. Tour. Res. 2000, 27, 371-390. [CrossRef]

54. Romanin, E.S.A. Entre el poder y la dominación. Los usos del monopolio en la sociología de Norbert Elías. Intersticios. Rev. Sociol. Pensam. Crít. 2009, 3, 231-239.

55. Caton, K. Taking the moral turn in tourism studies. Ann. Tour. Res. 2012, 39, 1906-1928. [CrossRef] 
56. Holmes, A.P.; Grimwood, B.S.; King, L.J.; Lutsel K'e Dene First Nation. Creating an Indigenized visitor code of conduct: The development of Denesoline self-determination for sustainable tourism. J. Sustain. Tour. 2016, 24, 1177-1193. [CrossRef]

57. Hang, P. Stakeholders of Angkor World Heritage site management. In Proceedings of the Personas y Comunidades: Actas del Segundo Congreso Internacional de Buenas Prácticas en Patrimonio Mundial, Madrid, Spain, 29 April-2 May 2015; pp. 525-536.

58. World Health Organization. A Joint Statement on Tourism and COVID-19-UNWTO and WHO Call for Responsibility and Coordination. Available online: https://www.who.int/news-room/detail/27-02-2020a-joint-statement-on-tourism-and-covid-19-unwto-and-who-call-for-responsibility-and-coordination (accessed on 12 August 2020).

Publisher's Note: MDPI stays neutral with regard to jurisdictional claims in published maps and institutional affiliations.

(C) 2020 by the authors. Licensee MDPI, Basel, Switzerland. This article is an open access article distributed under the terms and conditions of the Creative Commons Attribution (CC BY) license (http://creativecommons.org/licenses/by/4.0/). 